\title{
The functional interplay between EGFR overexpression, hTERT activation, and p53 mutation in esophageal epithelial cells with activation of stromal fibroblasts induces tumor development, invasion, and differentiation
}

\author{
Takaomi Okawa, ${ }^{1,2,3,8}$ Carmen Z. Michaylira, ${ }^{1,2,3,8}$ Jiri Kalabis, ${ }^{1,2,3}$ Douglas B. Stairs, ${ }^{1,2,3}$ \\ Hiroshi Nakagawa, ${ }^{1,2,3}$ Claudia D. Andl, ${ }^{1,2,3}$ Cameron N. Johnstone, ${ }^{1,2,3}$ Andres J. Klein-Szanto, ${ }^{4}$ \\ Wafik S. El-Deiry, ${ }^{2,3,5,6}$ Edna Cukierman, ${ }^{4}$ Meenhard Herlyn, ${ }^{7}$ and Anil K. Rustgi ${ }^{1,2,3,6,9}$ \\ ${ }^{1}$ Division of Gastroenterology, University of Pennsylvania, Philadelphia, Pennsylvania 19104, USA; ${ }^{2}$ Department \\ of Medicine, University of Pennsylvania, Philadelphia, Pennsylvania 19104, USA; ${ }^{3}$ Abramson Cancer Center, University \\ of Pennsylvania, Philadelphia, Pennsylvania 19104, USA; ${ }^{4}$ Division of Basic Science, Tumor Cell Biology, Fox Chase Cancer \\ Center, Philadelphia, Pennsylvania 19111, USA; ${ }^{5}$ Division of Hematology-Oncology, University of Pennsylvania, \\ Philadelphia, Pennsylvania 19104, USA; ${ }^{6}$ Department of Genetics, University of Pennsylvania, Philadelphia, Pennsylvania \\ 19104, USA; ${ }^{7}$ Wistar Institute, Philadelphia, Pennsylvania 19104, USA
}

Esophageal cancer is a prototypic squamous cell cancer that carries a poor prognosis, primarily due to presentation at advanced stages. We used human esophageal epithelial cells as a platform to recapitulate esophageal squamous cell cancer, thereby providing insights into the molecular pathogenesis of squamous cell cancers in general. This was achieved through the retroviral-mediated transduction into normal, primary human esophageal epithelial cells of epidermal growth factor receptor (EGFR), the catalytic subunit of human telomerase $(h T E R T)$, and $p 53^{R 175 H}$, genes that are frequently altered in human esophageal squamous cell cancer. These cells demonstrated increased migration and invasion when compared with control cells. When these genetically altered cells were placed within the in vivo-like context of an organotypic three-dimensional (3D) culture system, the cells formed a high-grade dysplastic epithelium with malignant cells invading into the stromal extracellular matrix (ECM). The invasive phenotype was in part modulated by the activation of matrix metalloproteinase-9 (MMP-9). Using pharmacological and genetic approaches to decrease MMP-9, invasion into the underlying ECM could be suppressed partially. In addition, tumor differentiation was influenced by the type of fibroblasts within the stromal ECM. To that end, fetal esophageal fibroblasts fostered a microenvironment conducive to poorly differentiated invading tumor cells, whereas fetal skin fibroblasts supported a well-differentiated tumor as illustrated by keratin "pearl" formation, a hallmark feature of well-differentiated squamous cell cancers. When inducible AKT was introduced into fetal skin esophageal fibroblasts, a more invasive, less-differentiated esophageal cancer phenotype was achieved. Invasion into the stromal ECM was attenuated by genetic knockdown of AKT1 as well as AKT2. Taken together, alterations in key oncogenes and tumor suppressor genes in esophageal epithelial cells, the composition and activation of fibroblasts, and the components of the ECM conspire to regulate the physical and biological properties of the stroma.

[Keywords: Cell migration and invasion; tumor microenvironment; EGFR; p53; MMP-9; AKT]

Supplemental material is available at http://www.genesdev.org.

Received February 22, 2007; revised version accepted September 5, 2007.

${ }^{8}$ These authors contributed equally to this work.
${ }^{9}$ Corresponding author.
E-MAIL anil2@mail.med.upenn.edu; FAX (215) 573-5412.
Article is online at http://www.genesdev.org/cgi/doi/10.1101/gad.1544507. 
Esophageal squamous cell carcinoma (ESCC) is one of the most aggressive squamous cell cancers compared with those originating at other sites, such as skin, head/ neck, lung, and anogenital tract. The reasons underlying these differences are somewhat surprising in that there is commonality in the type and frequency of pivotal genetic alterations and environmental exposures. In this context, the prognosis for patients with ESCC remains poor, due to the high rate of local and distant metastases at time of diagnosis (Enzinger and Mayer 2003). Common genetic alterations identified in ESCC include epidermal growth factor receptor (EGFR; up to $70 \%$ ) and cyclin D1 oncogene overexpression (up to $60 \%-70 \%$ ), inactivation of the $\mathrm{p} 53(50 \%-60 \%)$ and $\mathrm{p} 16^{\text {INK } 4 a}(40 \%-$ $50 \%$ ) tumor suppressor genes, and human telomerase (hTERT) activation (Mandard et al. 2000; Metzger et al. 2004; Sunpaweravong et al. 2005). Cyclin D1 and EGFR overexpression appears to be associated with early events in tumor initiation, in particular with preneoplastic (squamous dysplasia) and early neoplastic stages, whereas p53 and p16 inactivation is associated with tumor progression in advanced neoplastic stages (Mandard et al. 2000; Okano et al. 2003). While these are the canonical genetic alterations that delineate ESCC initiation and progression, genomic approaches have added to the library of other genes and pathways that are important, although not as compelling in terms of high frequency.

Genetic alterations in epithelial tumors, such as squamous cell cancers, help to drive tumor cell migration and invasion into the extracellular matrix (ECM). The mesenchymal stroma (or connective tissue) is essential for the maintenance of the epithelium. Genetically altered epithelial cells modify the stromal compartment so as to establish a permissive and supportive environment for cancer cell invasion (Unger and Weaver 2003). The fibroblasts are one of several cell types involved in the stromal compartment-mediated regulation of epithelial cancer (Beacham and Cukierman 2005). The fibroblastic population is very heterogeneous, and it varies from tissue to tissue and from site to site. It is, however, accepted to define fibroblasts as the cells responsible for producing, maintaining, and modifying the ECMs of connective tissue. These cells are normally spindled or stellate in shape and are responsible for maintaining homeostatic equilibrium in connective (or mesenchymal) compartments. Fibroblasts are characterized as being vimentin positive, E-cadherin negative, and spindleshaped in two-dimensional (2D) cultures as well as three-dimensional (3D) matrices (Amatangelo et al. 2005).

The fibroblasts in the cancer stroma are activated myofibroblasts or cancer-associated fibroblasts (Beacham and Cukierman 2005). In some cases, the trigger for neoplastic progression may come from signals within the stromal microenvironment (Radisky et al. 2001; Maffini et al. 2004). It is increasingly apparent that mesenchymal stromal fibroblasts modulate tumor cell migration and invasion through autocrine and paracrine mechanisms involving, in part, secreted growth factors and cytokines.
In addition, both epithelial cells and stromal fibroblasts produce enzymes that degrade the epithelial basement membrane, as well as the mesenchymal ECM (Liotta et al. 1991), such as matrix metalloproteinases (MMPs). Tumor cell invasion into the ECM with subsequent metastasis to distant organs via hematogenous and lymphatic dissemination are critical steps in tumor viability and progression (Gupta and Massague 2006).

In this study, we transduced EGFR, hTERT, and $\mathrm{p} 53^{\mathrm{R} 175 \mathrm{H}}$ (a frequently occurring p53 mutation in human esophageal cancer) genes into primary human esophageal epithelial cells and established an innovative and new esophageal cancer model using an in vivo-like organotypic 3D cell culture system. Furthermore, we found that activation of MMP-9 partially modulates tumor cell migration and invasion into the stromal ECM in organotypic culture. The model also unravels previously unrecognized differences in the biological behavior of different tissue sources of fibroblasts in fostering not only tumor migration and invasion, but also the degree of tumor differentiation (well differentiated or poorly differentiated), which are critical parameters in the histopathological grading of tumors and correlation with patient survival. Importantly, activated stromal fibroblasts exert their effects partially through the phosphorylation of $\mathrm{AKT}$, as proven through pharmacological and genetic manipulation of AKT.

\section{Results}

The combination of EGFR, hTERT, and mutant p53 induces a dysplastic epithelium and an invasive cancer phenotype that interacts with the mesenchymal stroma compartment

EGFR, hTERT, and $p 53^{R 175 H}$ were transduced into normal diploid or primary human esophageal epithelial cells (EPC2). EPC2 cells normally undergo replicative senescence after population doubling 40-45; however, this can be overcome through hTERT overexpression (Harada et al. 2003). In order to potentially transform parental EPC2-hTERT cells, wild-type EGFR and $p 53^{R 175 H}$ were introduced via retroviral transduction. These transduced cells demonstrate overexpression of EGFR, as well as stabilization of $\mathrm{p} 53^{\mathrm{R} 175 \mathrm{H}}$ as confirmed by Western blot analysis (Fig. 1A). Independent cell lines with retroviral transduction of EGFR and $p 53^{R 175 H}$ were generated (Supplementary Fig. 1A). EGFR phosphorylation in the EPC2-hTERT-EGFR-p53 ${ }^{\text {R175H }}$ cells was assessed following stimulation with EGF. All major phosphorylation sites analyzed (Y845, Y1045, Y1068, Y1173) were activated following EGF treatment (Supplementary Fig. 1B). Boyden chamber migration and Matrigel invasion assays revealed that EPC2-hTERT-EGFR-p53 ${ }^{\mathrm{R} 175 \mathrm{H}}$ cells harbor increased migration and invasion capabilities when compared with control cells (Fig. 1B,C).

In order to understand the biological relevance of these genetic alterations, an in vivo-like 3D organotypic cell culture system was used. To mimic the tissue microenvironment, epithelial cells were overlaid on an ECM gel 
Okawa et al.

A.

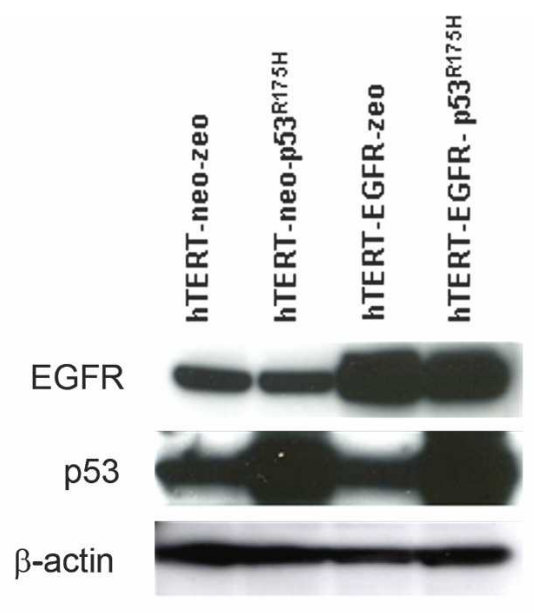

B.

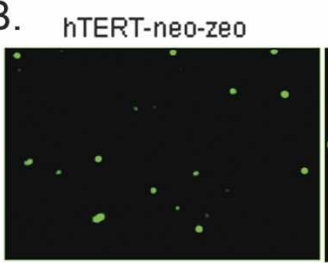

hTERT-neo-p53 ${ }^{\text {Riss }}$
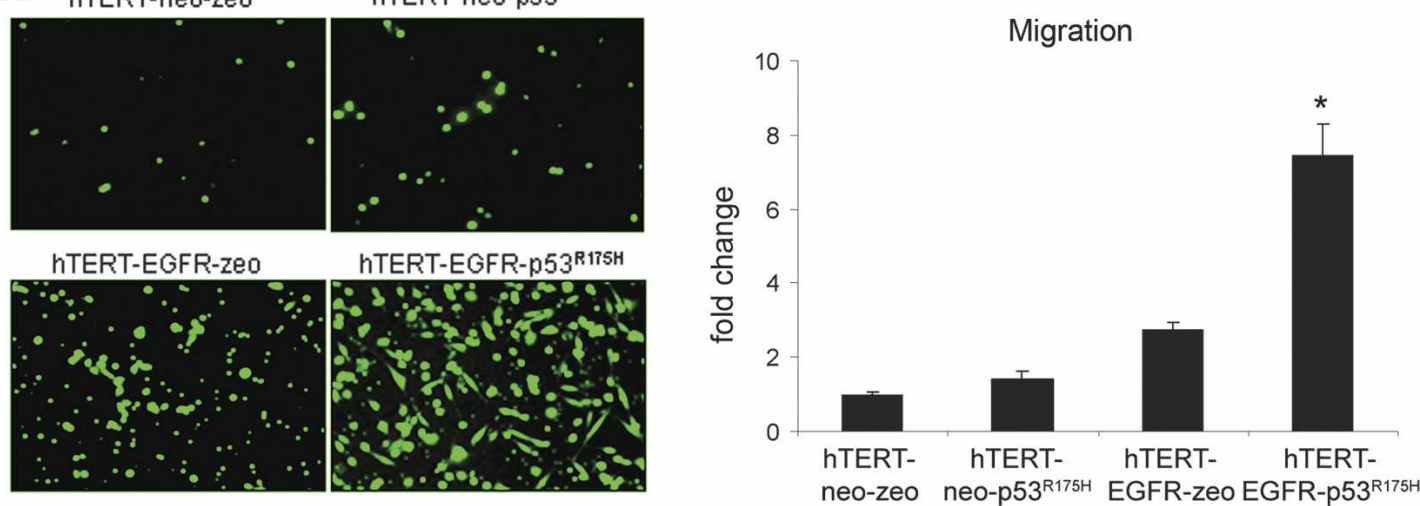

C. nTERT-neo-zeo

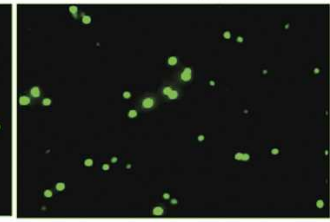

neo-zeo neo-p53 ${ }^{\text {R175H }}$ EGFR-zeo EGFR-p53 ${ }^{\text {R175 }}$
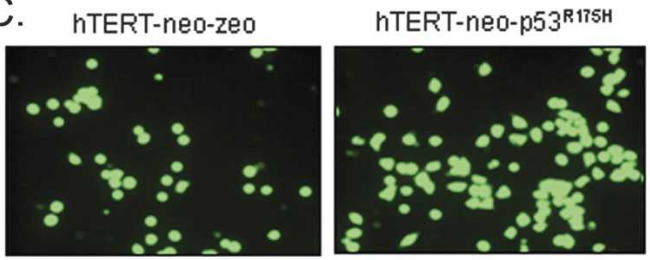

HTERT-EGFR-p53 $3^{\text {R175H }}$
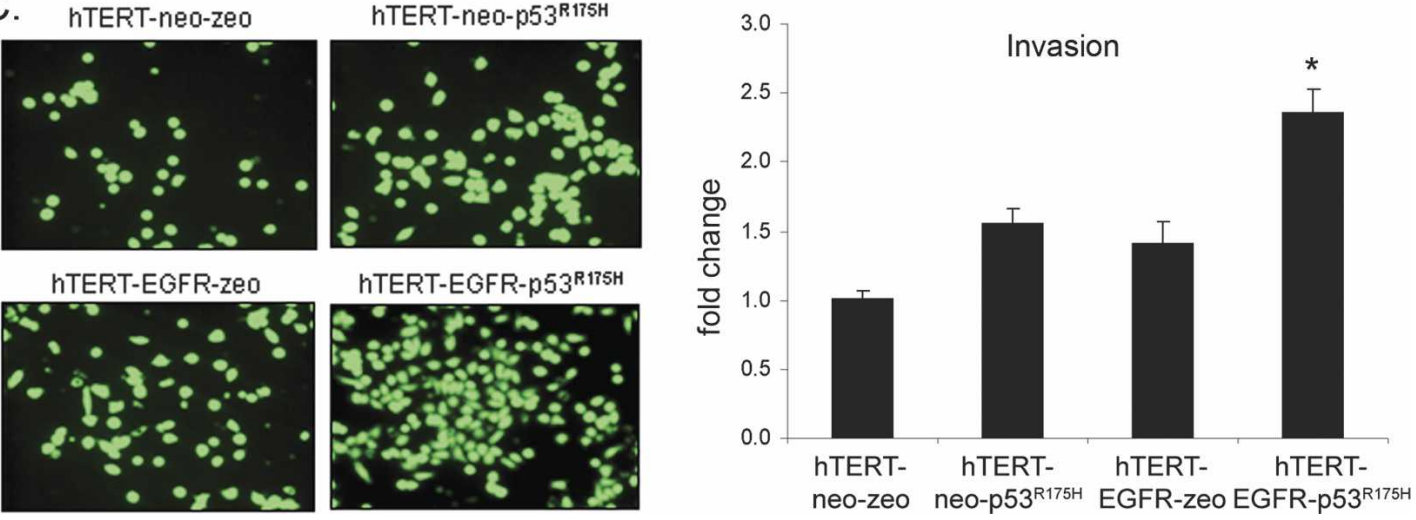

Figure 1. (A) Stable expression of $\mathrm{p} 53^{\mathrm{R} 175 \mathrm{H}}$ and/or EGFR in hTERT immortalized human esophageal epithelial cells detected by Western blot. (Lane 1) Control EPC2-hTERT-neo-zeo. (Lane 2) EPC2-hTERT-neo-p53 ${ }^{\text {R175H }}$. (Lane 3) EPC2-hTERT-EGFR-zeo. (Lane 4) EPC2-hTERT-EGFR-p53 ${ }^{\mathrm{R} 175 \mathrm{H}}$. (B) Fluorescent images acquired from the bottom filters of a Boyden chamber migration assay with comparisons of control EPC2-hTERT-neo-zeo, EPC2-hTERT-neo-p53 ${ }^{\text {R175H }}$ and EPC2-hTERT-EGFR-zeo, and EPC2-hTERT-EGFR$\mathrm{p} 53^{\mathrm{R} 175 \mathrm{H}}$ cells. Bar graphs represent fold changes $\pm \mathrm{SEM}_{;}\left(^{\star}\right) P \leq 0.002$ (Student $t$-test, EPC2-hTERT-EGFR-p53 ${ }^{\mathrm{R} 175 \mathrm{H}}$ vs. all controls). Note that $P<0.05$ is statistically significant. The data were obtained from three independent cell lines with all experiments performed in triplicate. $(C)$ Images and quantifications of the Matrigel invasion assay were acquired and processed as in $B$.

mixed with human fetal esophageal fibroblasts, and after $11 \mathrm{~d}$, a liquid-air interface was created, thereby leading to stratification of the squamous epithelium, which resembles the human esophageal squamous epithelium
(Andl et al. 2003; Harada et al. 2003; Oyama et al. 2007). The EPC2-hTERT-EGFR cells (Fig. 2A, panel c) revealed a hyperplastic epithelium in organotypic culture when compared with control cells (Fig. 2A, panel a), while 
A.
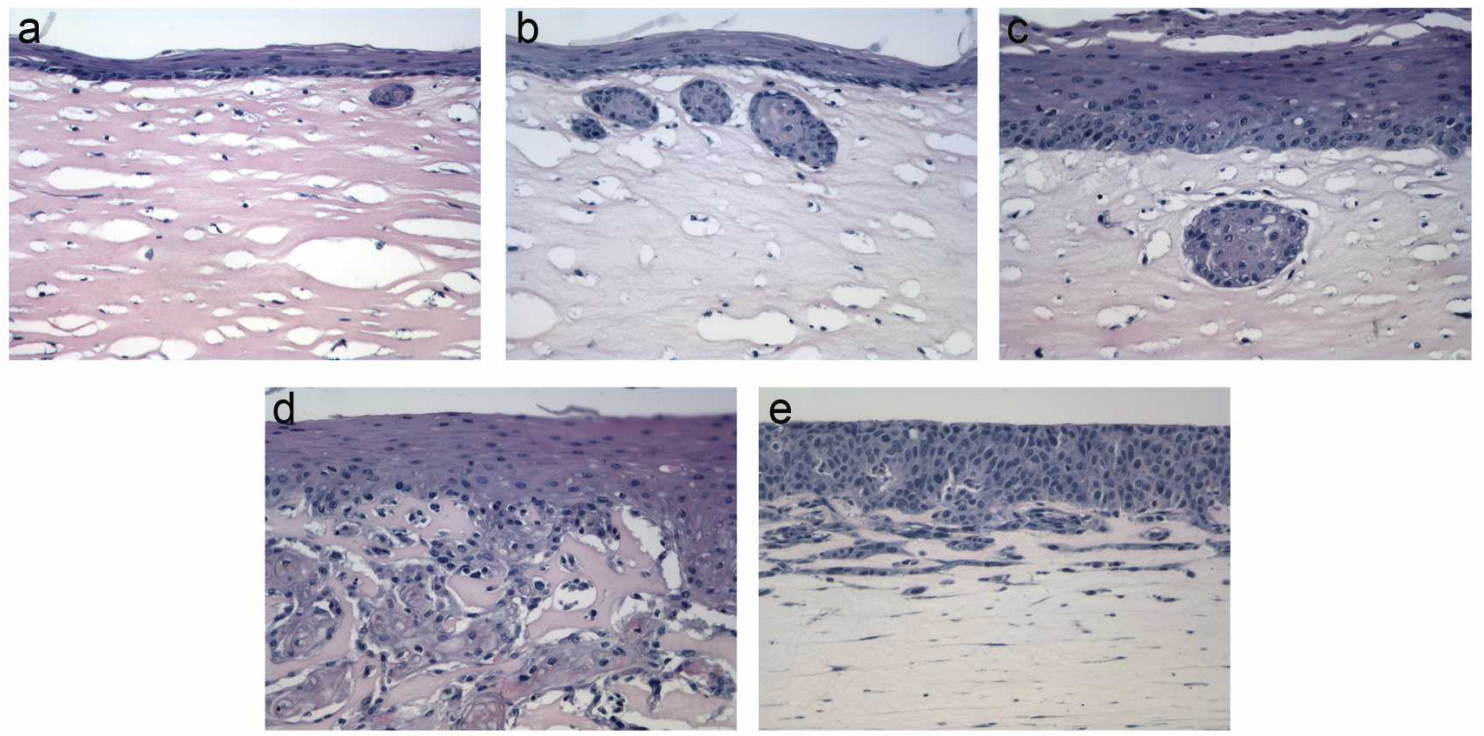

B.

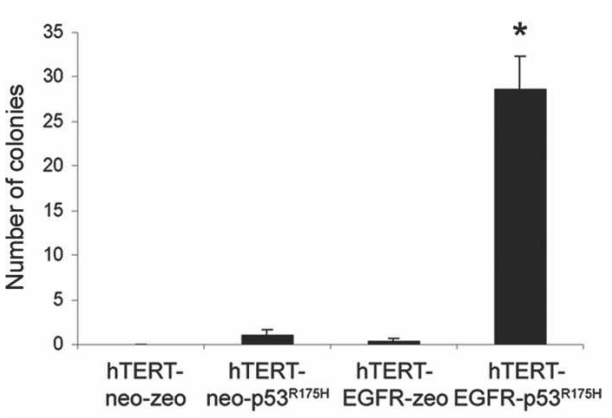

C.

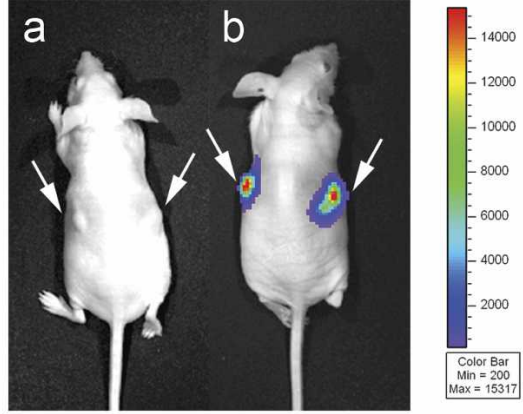

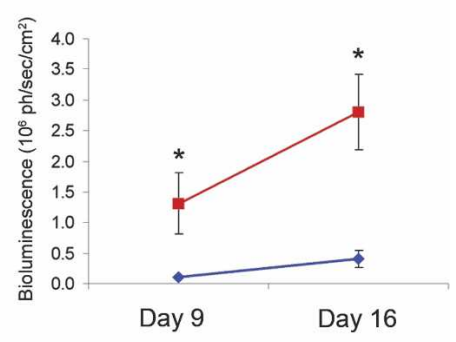

Day 9

Day 16

\begin{abstract}
D.
\end{abstract}
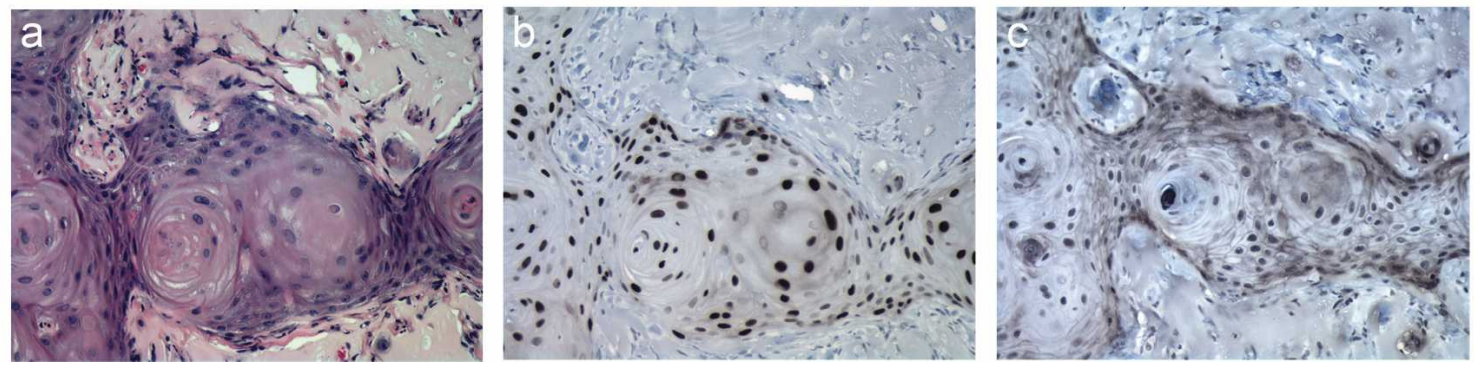

Figure 2. (A) H\&E staining of organotypic cultures of control EPC2-hTERT-neo-zeo (panel $a)$, EPC2-hTERT-neo-p53 ${ }^{\mathrm{R} 175 \mathrm{H}},(\mathrm{panel} b)$ and EPC2-hTERT-EGFR-zeo (panel $c$ ), as well as EPC2-hTERT-EGFR-p53 ${ }^{\text {R175H }}$ (panel $d$ ) and TE12 cancer cells (panel $e$ ) are shown. Note that there is dramatic invasion of EPC2-hTERT-EGFR-p53 ${ }^{\mathrm{R} 175 \mathrm{H}}$ cells into the mesenchymal matrix in a manner that is comparable with TE12 cells, a human esophageal cancer cell line $(120 \times)$. (B) Soft-agar assays demonstrated anchorage-independent growth of EPC2-hTERT-EGFR-p53 ${ }^{\mathrm{R} 175 \mathrm{H}}$ cells. The histograms show the average number of colonies \pm SEM; $\left(^{\star}\right) P \leq 0.002($ Student $t$-test; EPC2-hTERT-EGFR-p53 ${ }^{\mathrm{R} 175 \mathrm{H}}$ vs. all controls); $P<0.05$ is statistically significant. Assays were performed in triplicate. $(C)$ In vivo bioluminescence imaging of control EPC2-hTERT-EGFR-puro-Luc (panel $a$ ) and EPC2-hTERT-EGFR-p53 ${ }^{\mathrm{R} 175 \mathrm{H}-\mathrm{Luc}}$ (panel $b$ ) cells implanted subcutaneously into the dorsal skin of athymic nude mice. Tumor formation occurred only in EPC2-hTERT-EGFRp53 ${ }^{\mathrm{R} 175 \mathrm{H}}$ cells but not control cells. The graph demonstrates average bioluminescence signal (photons per second per square centimeter) \pm SEM for control (blue) and triple mutant (red) cells; $n=12$ injection sites per cell line; $\left(^{*}\right) P<0.02$ at day 9 and $P<0.002$ at day 16 after injection. $(D$, panel $a)$ H\&E staining of representative tumor formed in vivo by EPC2-hTERT-EGFR-p53 ${ }^{\text {R175H }}$ cells revealed a squamous cell carcinoma phenotype. Overexpression of $\mathrm{p}^{\mathrm{R}}{ }^{\mathrm{R} 175 \mathrm{H}}$ (panel $b$ ) and EGFR (panel $c$ ) in tumor cells was confirmed by immunohistochemistry $(120 \times)$.

p53 ${ }^{\mathrm{R} 175 \mathrm{H}}$ overexpression alone (Fig. 2A, panel b) had no significant effect when compared with the control cells.
However, both the EPC2-hTERT-EGFR-p53 ${ }^{\mathrm{R} 175 \mathrm{H}}$ cells (Fig. 2A, panel d) and the esophageal squamous cancer 
cell line, TE12 (Fig. 2A, panel e), known to be invasive and poorly differentiated, revealed high levels of invasion into the mesenchymal ECM. In addition, the EPC2hTERT-EGFR-p53 ${ }^{\mathrm{R} 175 \mathrm{H}}$ cells were poorly differentiated in the ECM, which is a hallmark feature of an aggressive ESCC. Similar results were observed using independent EPC2-hTERT-EGFR-puro and EPC2-hTERT-EGFRp53 ${ }^{\mathrm{R} 175 \mathrm{H}}$ cell lines (Supplementary Fig. 2). These results suggest that the specific combination of EGFR overexpression, hTERT induction, and p53 mutation are sufficient to transform normal human esophageal keratinocytes and phenocopy the classic features of human ESCC using an organotypic 3D culture model system.

The transformation potential of the EPC2-hTERTEGFR-p53 ${ }^{\mathrm{R} 175 \mathrm{H}}$ cells was also determined by soft-agar assays to test anchorage-independent growth. In these assays, the EPC2-hTERT-EGFR-p53 ${ }^{\text {R175H }}$ cells showed a statistically significant increase in the number of colonies formed compared with control cells (Fig. 2B). Additionally, the ability of EPC2-hTERT-EGFR-p53 ${ }^{\mathrm{R} 175 \mathrm{H}}$ cells to form tumors in vivo was assessed. For these studies, stable expression of the firefly luciferase gene (LuC) was achieved by retroviral transduction into EPC2hTERT-EGFR-p53 ${ }^{\text {R175H }}$ and control EPC2-hTERTEGFR-puro cells, and the luciferase activities of these cell lines were quantified (data not shown). EPC2hTERT-EGFR-puro-Luc and EPC2-hTERT-EGFR$\mathrm{p} 53^{\mathrm{R} 175 \mathrm{H}}$-Luc cells were subcutaneously injected into the dorsal flanks of immunodeficient mice. Tumor growth was monitored by bioluminescence measurements. Importantly, by day 16, tumor formation occurred in mice injected with EPC2-hTERT-EGFRp53 ${ }^{\mathrm{R} 175 \mathrm{H}}$-Luc cells but not in control cell lines (Fig. 2C). Tumors were excised for histological analysis that revealed a dramatic squamous cell carcinoma phenotype, which mimics precisely the morphology observed in the organotypic 3D culture model. Additionally, the overexpression of EGFR and mutant p53 in the tumor cells was confirmed by immunohistochemistry (Fig. 2D, panels $\mathrm{b}, \mathrm{c})$. Invasion of tumor cells into the surrounding stroma and muscle was confirmed, which is compatible with what was observed in organotypic culture, namely, invasion into the ECM (Supplementary Fig. 3).

MMP-9 is activated in invading triple mutant EPC2-hTERT-EGFR-p53 ${ }^{R 175 H}$ cells in organotypic $3 D$ cultures

To determine what factors might enable EPC2-hTERTEGFR-p53 ${ }^{\mathrm{R} 175 \mathrm{H}}$ cells to invade into the mesenchymal ECM, we performed gelatin zymography assays, thereby identifying the potential roles of secreted MMPs. To determine the temporal kinetics for MMP expression and activation, the conditioned media from organotypic 3D cultures were harvested at incremental time points. As shown in Figure 3A, EPC2-hTERT-EGFR-p53 ${ }^{\text {R175H }}$ cells begin to invade into the stromal ECM on day 11, with escalating invasion by days 13 and 15 . Therefore, conditioned media were harvested at days 11,13 , and 15 and analyzed by gelatin zymography. It should be em- phasized that stratification of the squamous epithelium only occurs after day 10 (Oyama et al. 2007). On day 11, there is faint expression of pro-MMP-9. On day 13, proMMP-9 is detected clearly, and active MMP-9 is detectable. On day 15 , active MMP-9 is prominent and proMMP-9 is decreased slightly (Fig. 3B). The relative levels of both pro- and active MMP-2 are unchanged (Fig. 3B); additionally, casein zymography failed to show differences in MMP-3, MMP-7, and MMP-10 that are detectable by this assay (data not shown). MMP-9 activation was confirmed independently as well. We performed an activation assay measuring the catalytically active form of MMP-9 in the organotypic culture-conditioned media. The assay provides specificity for MMP-9, using antibody-mediated capture of MMP-9, and permits distinction between pro- and active forms of MMP-9. There was a statistically significant increase of both active MMP-9 and pro-MMP-9 in EPC2-hTERT-EGFR-p53 ${ }^{\mathrm{R} 175 \mathrm{H}}$ cells when compared with control cells (Fig. 3C). This was further corroborated by MMP-9 real-time PCR (data not shown) and immunohistochemistry (Fig. 3D). In EPC2hTERT-EGFR-p53 ${ }^{\text {R175H }}$ cells, MMP-9 was expressed in the dysplastic basal layer of the epithelium and in the invading malignant cells in the mesenchymal ECM (Fig. 3D), similar to the MMP-9 expression pattern in TE-12 cancer cells. The immunohistochemical findings were corroborated by in situ gelatin zymography (data not shown).

MMP-9 inhibition alters invasion of EPC2-hTERTEGFR-p53 ${ }^{R 175 H}$ cells into the mesenchymal ECM

To address further the role of MMP-9, a genetic approach was pursued. MMP-9 short hairpin RNA (shRNA) was stably transduced into EPC2-hTERT-EGFR-p53 ${ }^{\text {R175H }}$ cells, resulting in decreased invasion using the Boyden chamber assay (Fig. 4A). These results were confirmed using an independent small interfering RNA (siRNA) sequence to MMP-9 (Fig. 4A). MMP-9 knockdown resulted in decreased invasion of EPC2-hTERT-EGFR-p53 ${ }^{\mathrm{R} 175 \mathrm{H}}$ cells in organotypic 3D cultures (Fig. 4B). Of note, MMP-9 knockdown was confirmed by Western blot analysis of EPC2-hTERT-EGFR-p53 ${ }^{\text {R175H }}$ cells (data not shown) and also by assessing MMP-9 activity (Supplementary Fig. 4). We next investigated an MMP-9-specific inhibitor to gauge its ability to reverse the invasive phenotype. The addition of an MMP-9 inhibitor to the organotypic culture medium decreased the invasive potential of EPC2-hTERT-EGFR-p53 ${ }^{\mathrm{R} 175 \mathrm{H}}$ cells to invade in a dose-dependent fashion (Fig. 4C). Moreover, TIMP1, a natural inhibitor of MMP-9, also decreased the invasive capacity of EPC2-hTERT-EGFR-p53 ${ }^{\mathrm{R} 175 \mathrm{H}}$ cells (data not shown). These results suggest that both the expression and the activation of MMP-9 are important for mediating the invasion of EPC2-hTERT-EGFR-p53 $3^{\text {R175H }}$ cells into the mesenchymal ECM.

The origin and type of stromal fibroblasts differentially modulate esophageal tumorigenesis

We found that the source of fibroblasts used in the organotypic culture is critical in fostering the extent of tu- 
A.

Day 11

Day 13

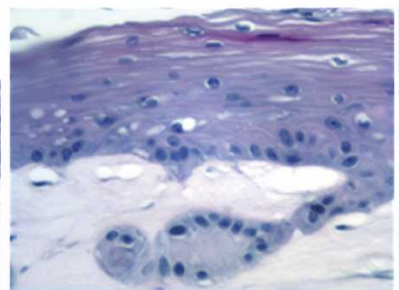

B.

D.
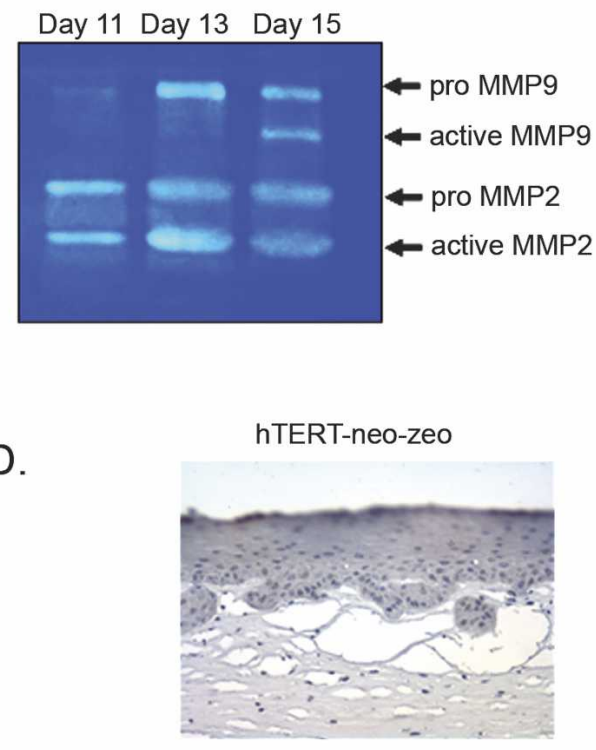

hTERT-EGFR-p53 $2175 \mathrm{H}$

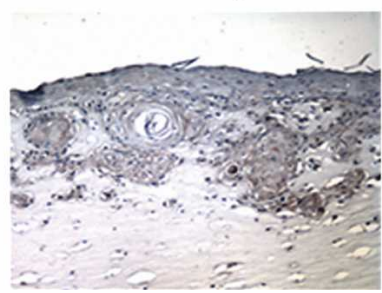

C.

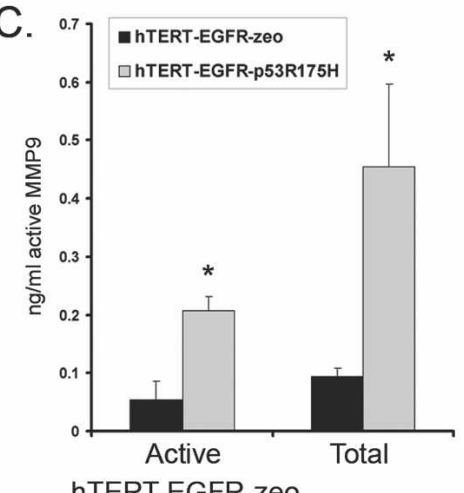

hTERT-EGFR-zeo

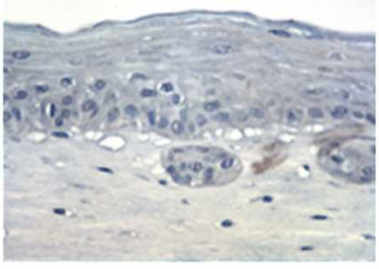

TE12

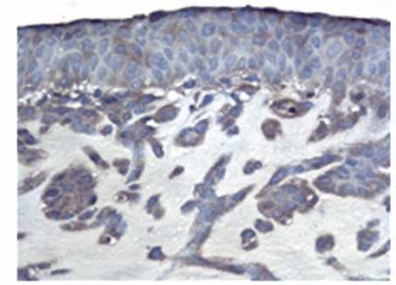

Figure 3. (A) Invasion of EPC2-hTERT-EGFR-p53 ${ }^{\mathrm{R} 175 \mathrm{H}}$ cells into the stromal matrix compartment was observed beginning on days 11 and 13 and in a completed form by day $15(240 \times)$. (B) Gelatin zymography revealing the pro- and activated forms of MMP-9 and MMP-2 obtained from the conditioned media of the organotypic 3D cultures at days 11, 13, and 15. (C) Specific enzymatic activity of MMP-9 secreted into the supernatant of organotypic cultures on day 15. Endogenously active MMP-9 alone (gray bars) and endogenously active MMP-9 together with AMPA-activated pro-MMP-9 (black bars) were measured $(n=8)$ in duplicate; $\left(^{*}\right) P<0.05$, Student $t$-test; $P<0.05$ is statistically significant. $(D)$ Immunohistochemistry of MMP-9 in control EPC2-hTERT-neo-zeo, EPC2-hTERTEGFR-zeo, EPC2-hTERT-neo-p53 ${ }^{\text {R175H }}$, EPC2-hTERT-EGFR-p53 ${ }^{\text {R175H }}$, and TE12 esophageal cancer cells (120×). Increased MMP-9 expression is observed in the invading growths of EPC2-hTERT-EGFR-p53 ${ }^{\mathrm{R} 175 \mathrm{H}}$ and TE12 cells.

mor invasion and the degree of tumor differentiation. For these studies, fibroblasts were isolated as described in Materials and Methods and characterized as being vimentin positive and E-cadherin negative (Fig. 5A) as well as spindle-shaped in $2 \mathrm{D}$ cultures and $3 \mathrm{D}$ matrices. Comparisons were made between human adult esophageal and fetal esophageal fibroblasts, and human fetal skin fibroblasts. When fetal skin fibroblasts were used, welldifferentiated ESCCs were found to be evident within the stromal ECM, with the distinctive hallmark feature of keratin "pearl" formation (Fig. 5B). In addition, there was evidence of invasive epithelial down-growth, which might correlate with a better prognosis in human esophageal cancers. However, employment of fetal esophageal fibroblasts within the mesenchymal ECM resulted in a more aggressive invasion with a tendency toward a poorly differentiated ESCC phenotype (Fig. 5B). Interestingly, human adult esophageal fibroblasts appear to be less primed or activated, as there is little evidence of invasion of tumor cells into the mesenchymal ECM (Fig. 5B). Increased invasion was also observed in three independent fetal esophageal fibroblast cell lines 
Okawa et al.

A.

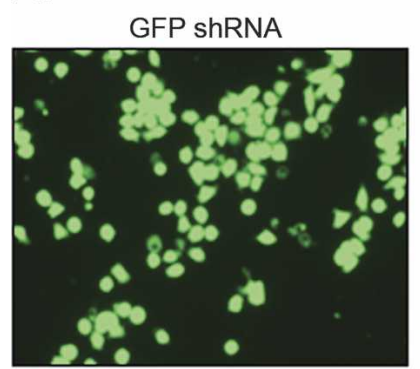

control siRNA

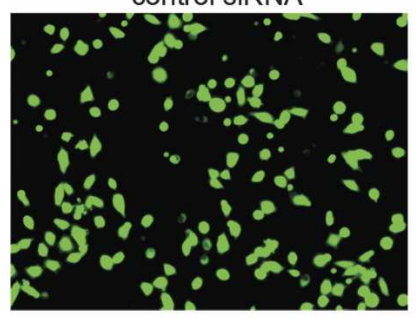

B.

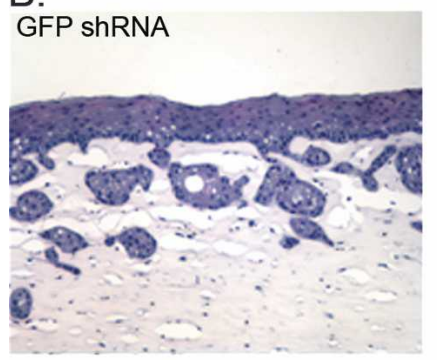

C.

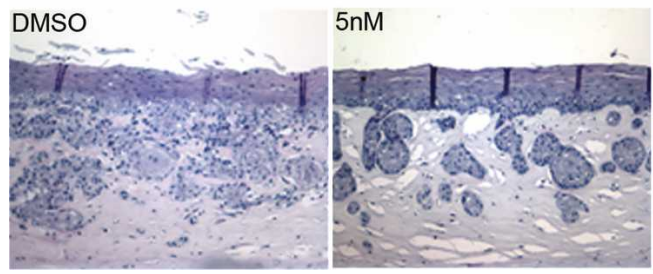

MMP9 shRNA

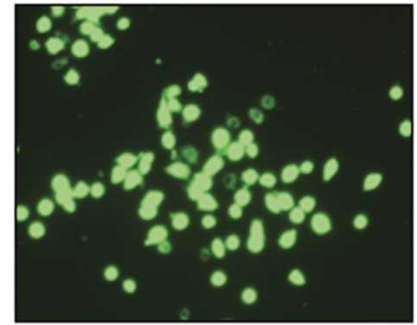

MMP9 siRNA

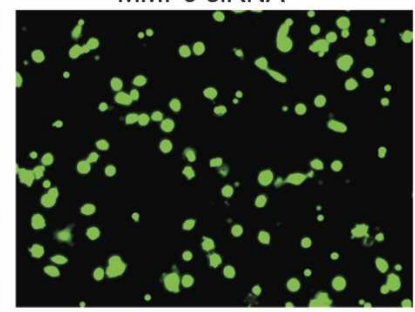

MMP9 shRNA

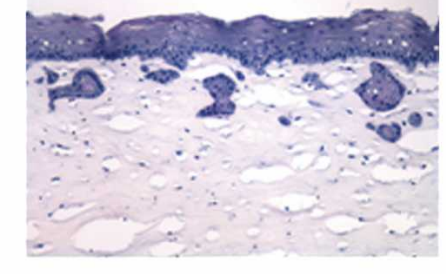

$50 \mathrm{nM}$
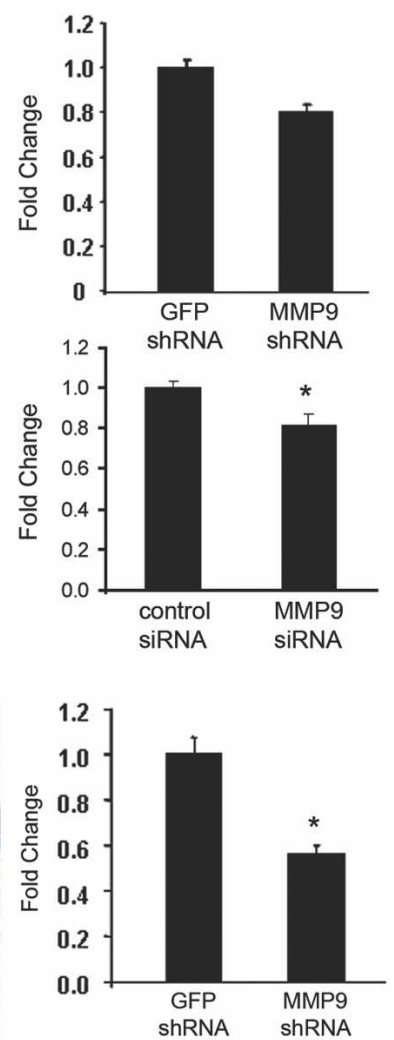

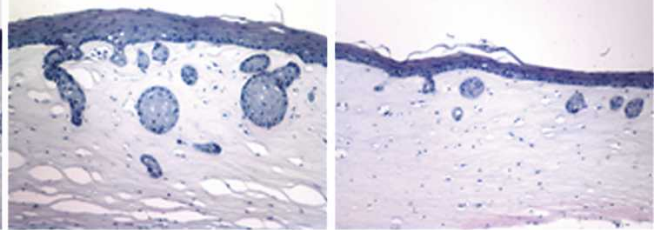

Figure 4. (A) Images and accompanying quantified bar graphs showing reduced invasion EPC2-hTERT-EGFR-p53 ${ }^{\mathrm{R} 175 \mathrm{H}}$ cells expressing shRNA to MMP-9 versus control shRNA to GFP in the Matrigel invasion assay. These data were verified using an independent siRNA sequence to MMP-9 and control siRNA. Experiments were performed in triplicate; $P=0.06$ for shMMP9 vs. shGFP; $\left({ }^{\star}\right) P<0.04$ for MMP9 siRNA vs. control siRNA. (B) H\&E staining of organotypic 3D culture comparing shRNA to MMP-9 versus control shRNA to GFP and accompanying quantified bars showing reduced invasion of EPC2-hTERT-EGFR-p53 ${ }^{\text {R175H }}$ cells with shRNA to MMP-9. Bar graphs represent fold change in invasion \pm SEM; $\left(^{*}\right) P<0.02$ (shMMP9 vs. shGFP). (C) H\&E staining demonstrating a dosedependent effect of MMP-9 inhibition on the invasive malignant phenotype of EPC2-hTERT-EGFR-p53 ${ }^{\mathrm{R} 175 \mathrm{H}}$ cells (120×).

(FEF3303, FEF2008, and FEF9003) using independent EPC2-hTERT-EGFR-p53 ${ }^{\mathrm{R} 175 \mathrm{H}}$ cell lines compared with control cells, while no invasion was observed in an independent adult esophageal fibroblast cell line (HEF) with any of the epithelial cells tested. (Supplementary Fig. 5). These results suggest that the source and the level of activity of stromal fibroblasts play divergent roles in permitting or restraining tumor cell invasion.

Fetal esophageal fibroblasts induce increased stiffness of the ECM

The mesenchymal ECM provides a mechanosensing (or physical) support structure that can either obstruct or facilitate tumor cell invasion, apart from known biological factors, which also affect the invasive behavior (Paszek and Weaver 2004; Paszek et al. 2005). In establishing our organotypic 3D culture model, we tested the role of different ECMs. Invasion of EPC2-hTERTEGFR-p53 ${ }^{\mathrm{R} 175 \mathrm{H}}$ cells into the stromal ECM was only observed in matrices containing a combination of type I collagen/Matrigel (3:1) with fetal skin or esophageal fibroblasts (Fig. 5; data not shown). The stiffness of the different matrices was measured to assess the physical contributions of the different components. Interestingly, the combination of type I collagen and Matrigel leads to a stiffer matrix compared with collagen alone, which 
A.

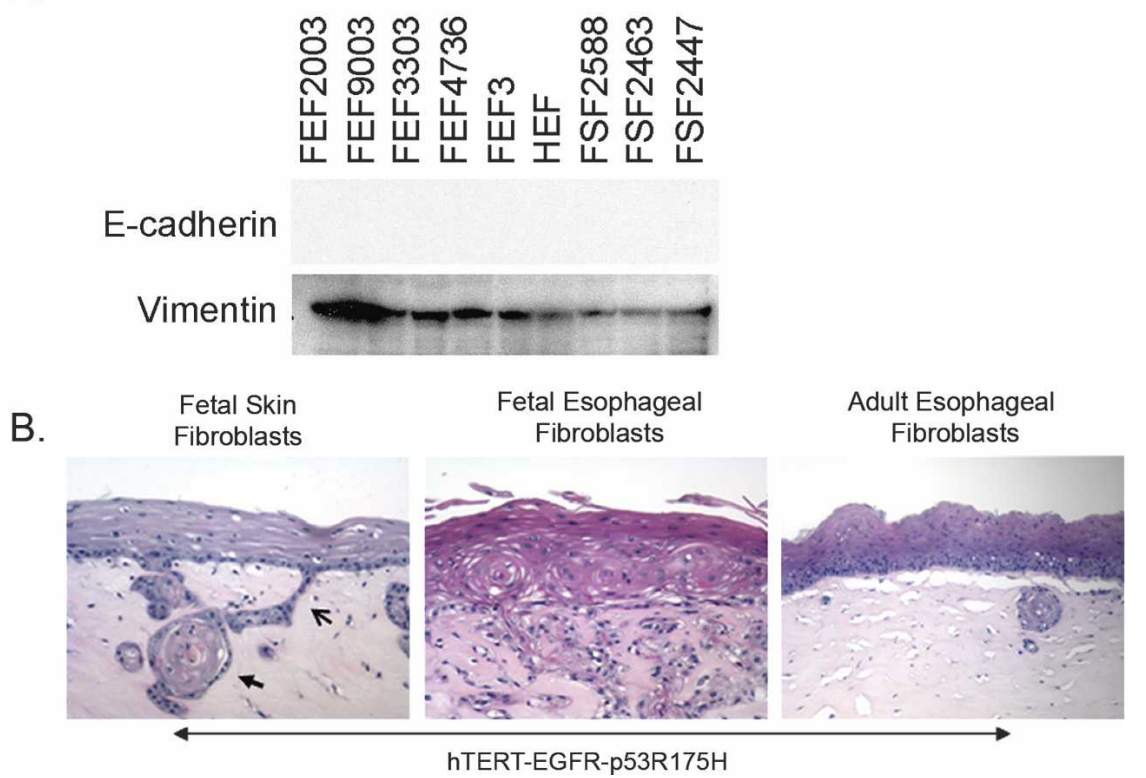

Figure 5. (A) Western blot analysis to assess the presence of vimentin and absence of E-cadherin in human fetal esophageal fibroblasts (FEF), adult esophageal fibroblasts (HEF), and human fetal skin fibroblasts (FSF). (B) H\&E staining of organotypic cultures of EPC2-hTERT-EGFR$\mathrm{p} 53^{\mathrm{R} 175 \mathrm{H}}$ cells as a function of varying the origin of the stromal fibroblasts-fetal skin, fetal esophageal, or adult esophageal-in the stromal 3D matrix (120x). The invasive phenotype of EPC2-hTERTEGFR-p53 ${ }^{\mathrm{R} 175 \mathrm{H}}$ cells reveals hallmark features observed in human esophageal cancer-namely, keratin "pearl" formation (closed arrow) and epithelial down-growth (open arrow), largely observed with fetal skin fibroblasts. The fetal esophageal fibroblasts demonstrate a more aggressive, poorly differentiated phenotype, while the adult esophageal fibroblasts do not result in significant invasion.

showed no invasion (Supplementary Fig. 6A; data not shown). The addition of fibroblasts to this collagen/Matrigel matrix resulted in an even greater increase in stiffness, and fetal esophageal fibroblasts gave rise to a stiffer matrix compared with fetal skin fibroblasts (Supplementary Fig. 6A). These differences in the physical properties of the matrices also may contribute to the differences in invasive phenotypes observed between fetal skin and fetal esophageal fibroblasts.

\section{AKT is up-regulated in cancer-associated fibroblasts with induction of invasive tumor behavior}

The differences in invasion that are facilitated by the various stromal fibroblasts may be due to soluble growth factors and/or cytokines secreted by the fibroblasts and/ or squamous epithelial tumor cells. We sought to examine AKT as a frequent effector of the signal transduction pathways from these growth factors and cytokines. AKT is a known pivotal modulator of survival in different cell types, and has been implicated in playing a role in tumor cell migration and invasion, but its role in stromal fibroblasts within the tumor microenvironment requires elucidation. Thus, we next examined AKT expression in the different fibroblasts. As shown in Figure 6A, Western blot analyses showed that phospho-AKT expression (AKT-Ser 473) is higher in fetal esophageal fibroblasts, which induce a more aggressive invasive phenotype, when compared with the phospho-AKT levels of fetal skin or adult esophageal fibroblasts. We next retrovirally transduced an inducible AKT gene into the fibroblasts (see Materials and Methods) as a genetic approach. The AKT used is myristoylated and fused to the estrogen receptor, ensuring proper localization to the plasma membrane, where it can be induced by tamoxifen (Kohn et al. 1998). Induction of increasing levels of phospho-AKT was accomplished in each of the various fibroblast cell lines by addition of tamoxifen in a dose-dependent manner (Fig. 6B; data not shown). When AKT-overexpressing fetal esophageal and adult esophageal fibroblasts were used in the organotypic culture system, the invasive areas were increased significantly (Fig. 6C). A significant increase in invasive area was also observed with fetal skin fibroblasts overexpressing AKT (Fig. 6C).

In order to underscore the role of AKT in stromagenesis-that is, the involvement of stromal fibroblasts in epithelial tumor migration and invasion-we pursued genetic and pharmacological approaches that are complementary to the overexpression experiments. AKT expression was attenuated in fibroblasts using validated siRNAs to AKT1 and AKT2 (Fig. 7A). Reduced invasion of EPC2-hTERT-EGFR-p53 ${ }^{\mathrm{R} 175 \mathrm{H}}$ cells was observed into matrices containing fibroblasts with attenuated AKT1 or AKT2 expression (Fig. 7B,C). These results were confirmed through the use of independent shRNAs to AKT1 and AKT2 with stable knockdown of AKT1 or AKT2 expression in fibroblasts (Supplementary Fig. 7). Pharmacologically, the addition of the AKT inhibitor AKTi $1 / 2$, which inhibits both AKT1 and AKT2, to the fibroblasts resulted in decreased phospho-AKT expression in a dose-dependent fashion (Fig. 7D). Invasion into the ECM was reduced with the AKTi $1 / 2$ inhibitor (Fig. 7E). Interestingly, addition of the AKTi $1 / 2$ inhibitor also resulted in a decreased matrix stiffness (Supplementary Fig. 6B). AKT activation is therefore likely to contribute to the differences in the invasive phenotype observed with the different fibroblasts.

\section{Discussion}

Squamous epithelial transformation occurs in the context of a dynamically changing 3D tissue that consists of multiple cell types, chief of which is the epithelium, 
Okawa et al.

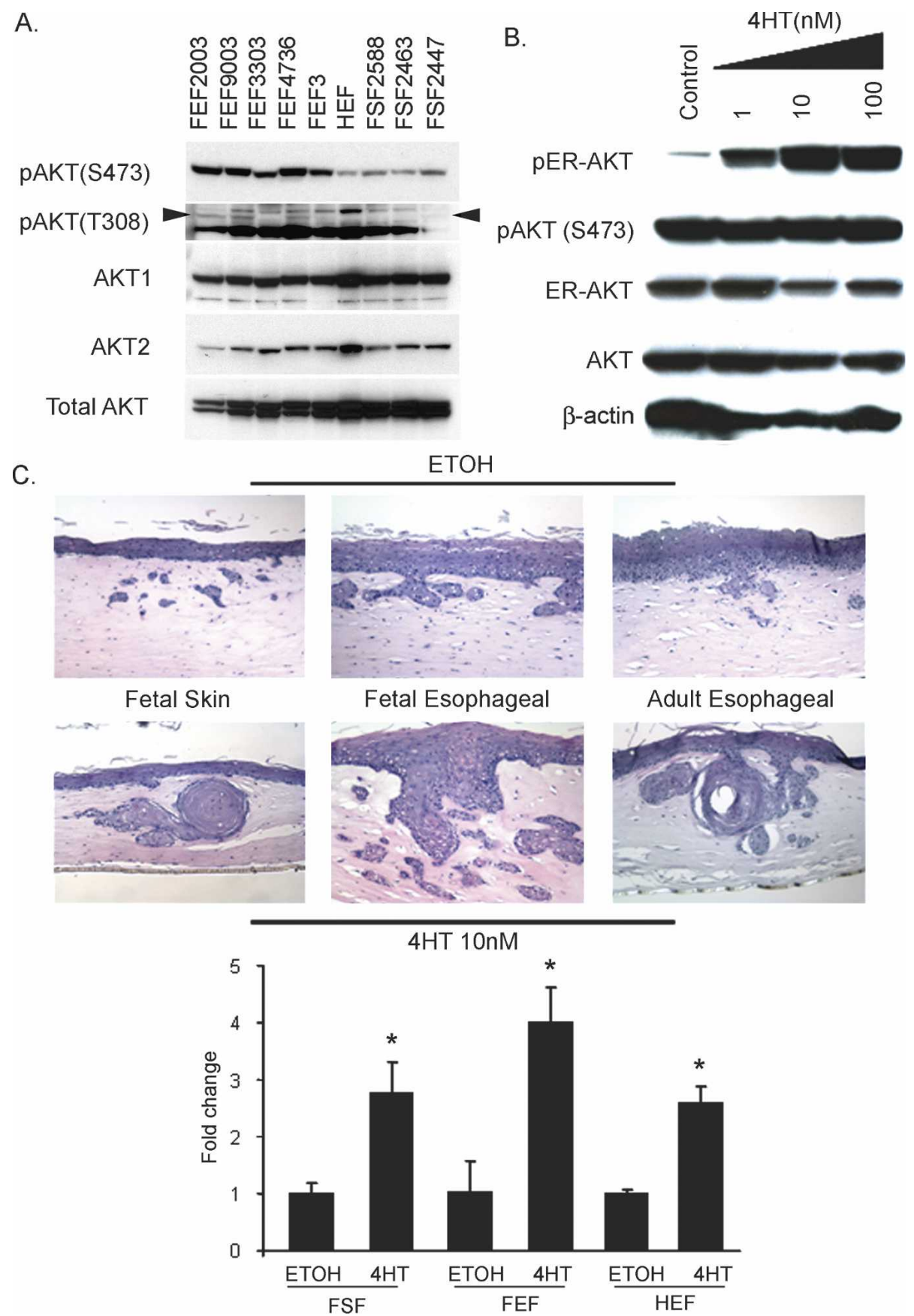

Figure 6. (A) Representative Western blot of activated phospho-AKT (S473 and T308) and total AKT, AKT1, and AKT2 levels expressed by assorted fibroblast cell lines. (B) Fibroblasts were infected with pWXL-myrAKT-HA-ER and then stimulated by 4-hydroxy-tamoxifen (4-HT) at variable concentrations. Levels of ectopic phospho-ER-AKT, endogenous phospho-AKT (S473), total ERAKT, and $\beta$-actin are shown. As an illustration, the Western blot for fetal skin fibroblasts is depicted, although similar results were obtained when fetal esophageal or adult esophageal fibroblasts were used (data not shown). (C) H\&E staining of organotypic cultures depicting the consequences of phospho-ER-AKT overexpression in the different fibroblasts on the nature and extent of invasion of EPC2-hTERT-EGFR-p53 ${ }^{\text {R175H }}$ cells (60×). Bars depict fold change in invasion between ethanol (vehicle control) versus $10 \mathrm{nM} 4-\mathrm{HT}$ treatment $\pm \mathrm{SEM}_{;}\left({ }^{\star}\right) P<0.08$ (FSF: ETOH vs. 4-HT), $P<0.007$ (FEF: ETOH vs. 4-HT), $P<0.03$ (HEF: ETOH vs.4-HT).

embedded within a complex, organized ECM. Compelling data indicate that tissue architecture and the mesenchymal stroma play an active role in tumorigenesis (Maffini et al. 2004; Beacham and Cukierman 2005). In this study, we used esophageal squamous epithelial cells as a platform and also as a paradigm for the better understanding of squamous cell cancers. Indeed, squamous cell cancers arising from the skin, head/neck, esophagus, lung, and anogenital tract constitute the most common cancer types. 
A.

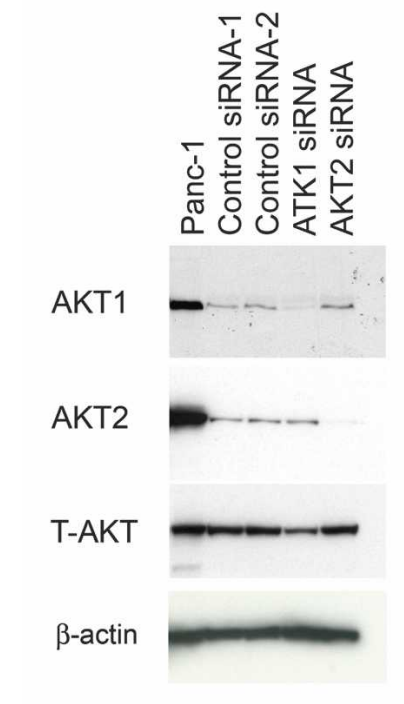

C.

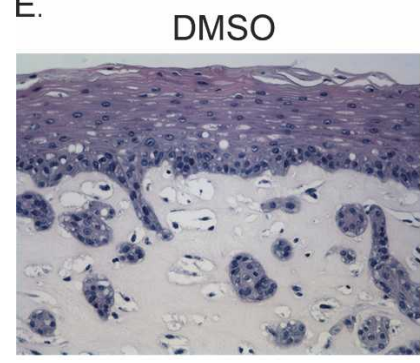

B.
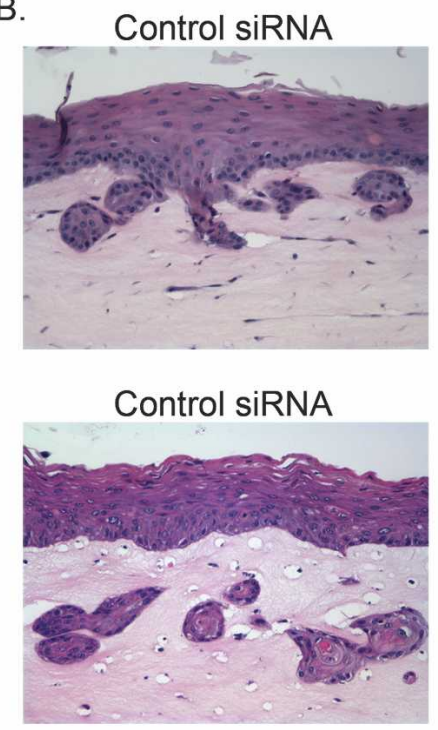

D.
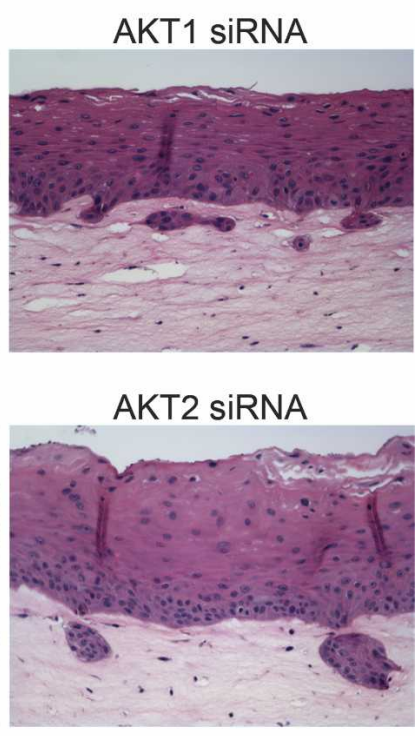

AKTi 1/2 (mM)
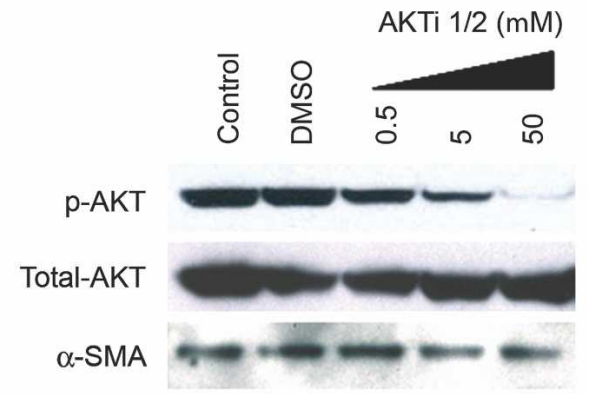
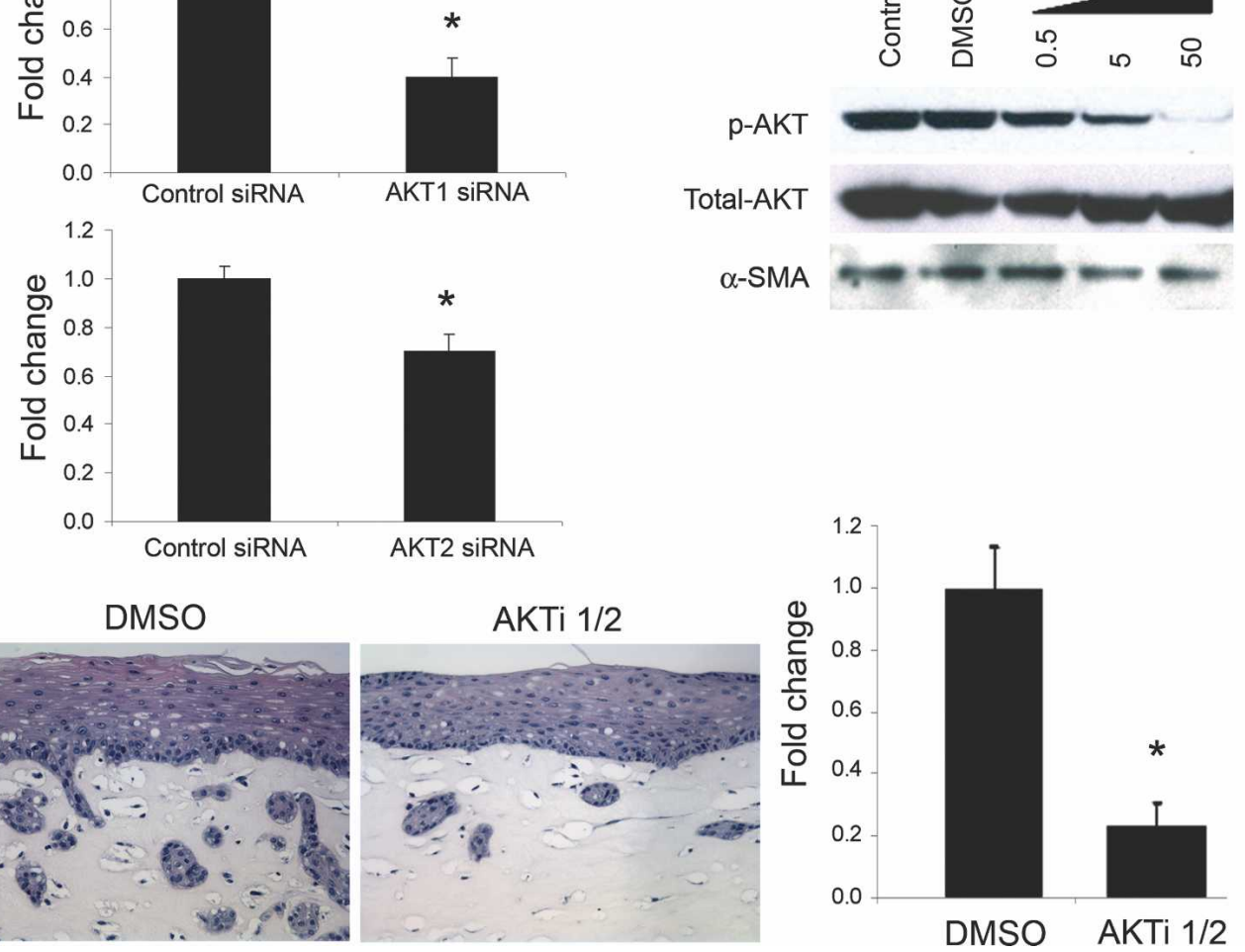

Figure 7. (A) Knockdown of AKT in fibroblasts by siRNAs to AKT1 and AKT2 was confirmed by Western blot analysis; $\beta$-actin was used as a loading control. (B) H\&E staining of organotypic 3D cultures comparing EPC2-hTERT-EGFR-p53 ${ }^{\mathrm{R} 175 \mathrm{H}}$ cell invasion into matrices containing fibroblasts with knockdown of AKT1 and AKT2 versus control siRNAs. (C) Bar graphs represent fold change in invasion $\pm \mathrm{SEM}_{;}\left(^{*}\right) P<0.002$ (AKT1 siRNA vs. control siRNA), $\left(^{\star}\right) P<0.005$ (AKT2 siRNA vs. control siRNA). (D) The effects of AKT inhibition with AKTi 1/2 on phospho-AKT in fetal esophageal fibroblasts. (E) H\&E staining of organotypic cultures and accompanying quantified bars demonstrating reduced invasion of EPC2-hTERT-EGFR-p53 R175H cells into the underlying stromal ECM in the presence of the AKT1/2 inhibitor $(24 \times)$; bar graphs represent fold change in invasion versus DMSO $\left(\right.$ vehicle control) $\pm \mathrm{SEM}^{*}\left({ }^{\star}\right)$ $P<0.001$ (AKTi $1 / 2$ vs. DMSO).

ESCC is a highly malignant gastrointestinal cancer that is associated with a high mortality rate (Enzinger and Mayer 2003). The poor prognosis associated with this type of cancer is due to the fact that most patients 
are not diagnosed until late stages of disease (Nair et al. 2005). The development of ESCC is a progressive multistep process, starting with increases in esophageal epithelial cell proliferation, leading to basal cell hyperplasia, dysplasia, carcinoma in situ, and finally advanced carcinoma (Lehrbach et al. 2003). At the late stages of disease, tumor invasion plays a key role in influencing patient survival (Nair et al. 2005). Interestingly enough, the prognosis of ESCC is poor compared with other squamous cell carcinomas originating at other sites, suggesting that the local tumor microenvironment might be very critical in accounting for these differences.

Multiple genetic alterations are involved in the development of ESCC (McCabe and Dlamini 2005). These include amplification of oncogenes, including cyclin D1 and EGFR, and mutations in tumor suppressor genes, including $p 53$ and $p 16 I N K 4 a$. These are common alterations observed in other squamous cell carcinomas. EGFR is overexpressed frequently in early-stage esophageal cancer and correlates with a poor prognosis (Ozawa et al. 1989). P53 is one of the most commonly mutated genes in human cancer (Vogelstein and Kinzler 2004). The majority of p53 mutations occur in the in the DNAbinding domain, and $>80 \%$ of these mutations are missense mutations, thereby leading to a dominant-negative effect and resulting in loss of wild-type p53 function (Sengupta and Harris 2005). The particular $p 53^{R 175 H} \mathrm{mu}-$ tation used in this study is a missense mutation that abrogates protein-DNA contact by disrupting protein conformation (Joerger et al. 2005).

The combination of EGFR overexpression, hTERT activation, and p53 mutation conspires to induce invasive ESCC

We believe that esophageal squamous epithelial transformation, achieved by alterations in EGFR, hTERT, and p53, is triggered in part by modulation in the stromal ECM by activated or tissue-specific fibroblasts to create a microenvironment that nurtures tumor cell migration resulting in efficient invasive tumor cell behavior. In particular, EPC2-hTERT-EGFR-p53 ${ }^{\mathrm{R} 175 \mathrm{H}}$ cells reveal high-grade dysplasia in the basal compartment of the epithelium and a dramatic, fibroblastic-type-dependent invasive phenotype within the mesenchymal ECM. There is accompanying induction of active MMP-9, but not MMP-2, in organotypic 3D culture. Consistent with our notion of MMP9 activation, our preliminary gene array data, using the Human Genome U133 Plus 2.0 Array (Affymetrix) of total RNAs isolated from five pairs of primary ESCC tissues and adjacent normal mucosa, have revealed MMP-9 up-regulation (21-fold) but no significant change of MMP2 mRNA (H. Nakagawa, Y. Naomoto, and A.K. Rustgi, unpubl.). Additionally, upon employing laser capture microdissection (LCM) of the invasive malignant EPC2-hTERT-EGFR-p53 ${ }^{\text {R175H }}$ cells versus the noninvasive dysplastic epithelium from organotypic culture with subjecting the total RNAs to the same Array platform, we find induction of MMP-9
mRNA (fourfold induction) in the invasive cells compared with the noninvasive cells (C.Z. Michaylira and A.K. Rustgi, unpubl.). The differences in the extent of MMP-9 mRNA induction may be attributable to the evolution of malignancy between organotypic 3D culture (initiating phase) and primary ESCC.

In a tumor, the close proximity of neoplastic and nonneoplastic cells (e.g., fibroblasts, pericytes, and inflammatory, endothelial, and myoepithelial cells) affects the microenvironment of the ECM (Wittekind and Neid 2005). Several gene families are involved in tumor invasion: MMPs, urokinase plasminogen activator/receptor, integrins, and cathepsins (Mannello et al. 2005; Vihinen et al. 2005). The MMPs are a family of zinc-dependent peptidases, which are capable collectively of degrading many ECM components. MMP-2 and MMP-9 mainly degrade type IV collagen, which is the main component of the basement membrane (Mannello et al. 2005; Vihinen et al. 2005). MMP-2 and MMP-9 activation has been proposed to be critical for carcinoma progression since the proteolytic ability of type IV collagen is associated with cancer metastatic ability (Liotta et al. 1980, 1991). Several reports have indicated that MMPs are associated with the malignant potential of esophageal cancer (Koyama et al. 2000; Polette et al. 2004; Samantaray et al. 2004; Gu et al. 2005). Interestingly, Kim et al. (1998) demonstrated that MMP-9 activity, and not MMP-2 activity, could significantly affect tumor intravasation into blood vessels by degrading the basement membrane. Moreover, the level of telomerase activity has been shown to correlate with the degree of invasion (Lin et al. 1996; Engelhardt et al. 1997; Zhang et al. 1999; Simon et al. 2000; Sato et al. 2001; Mitsui et al. 2002).

How are EGFR and MMP-9 related? The role of ERK and p38 MAPKs in MMP-9 gene expression has been well documented (Boyd 1996; Simon et al. 1998; McCawley et al. 1999; Reddy et al. 1999; Zeigler et al. 1999). Reddy et al. (1999) reported that PI3K inhibition only partially blocks EGF induction of MMP-9 expression in breast epithelial cells, whereas both invasion and MMP-9 production are significantly dependent on MEK. Moreover, EGFR activation promotes a PI3K-dependent induction of a cell surface pro-MMP-9-binding component (Ellerbroek et al. 2001). Little is known about the regulation of the active form of MMP-9. Our results suggest that $p 53$ and EGFR might cooperate to regulate the activation of MMP-9.

In this study, we used complementary genetic and pharmacological approaches to attenuate MMP-9 activity in order to suppress invasion by the EPC2-hTERTEGFR-p53 ${ }^{\mathrm{R} 175 \mathrm{H}}$ cells into the mesenchymal ECM, underscoring a direct role for MMP-9 activation in ECM degradation. Indeed, the MMP-9 promoter is active specifically in invasive mammary tumors and skin tumors in mouse models (Kupferman et al. 2000). While MMP-9 inhibition in human clinical trials has not achieved the desired success, it is possible that it needs to be applied in early-stage invasive, nonmetastatic tumors. Of note, our studies suggest a potential relationship between concordant up-regulation of EGFR and MMP-9, as has been 
suggested in non-small-cell lung cancer (Cox et al. 2000), and thus, combinatorial therapy against EGFR and MMP-9 may have conceptual merit.

\section{Stromagenesis influences tumorigenesis}

Stromagenesis is used to describe the progressive changes that stroma undergoes during the process of epithelial tumorigenesis. Specifically, the term describes tumor-associated changes in fibroblasts and fibroblastderived ECM. Currently, it is believed that tumor cells can both influence and be influenced by their stromal microenvironment, and that some stromas are genetically and/or epigenetically more suitable than others to support tumorigenesis and metastases (Beacham and Cukierman 2005). The system presented herein specifically demonstrates that the nature (or activation level) of fibroblasts is key in promoting or repressing the invasive ability of ESCC. There are dramatic differences observed between fetal esophageal, fetal skin, and human adult esophageal fibroblasts, suggesting that autocrine and paracrine pathways are important and mediated by yetto-be-identified soluble growth factors and/or cytokines. We do find compelling and, we believe, novel evidence for phosphorylated AKT in modulating invasion into the mesenchymal ECM as revealed by genetic and pharmacological manipulation of AKT in stromal fibroblasts. Inducible overexpression of AKT in stromal fibroblasts facilitates invasion, whereas genetic knockdown or pharmacological inhibition of either AKT1 or AKT2 attenuates invasion. The underlying basis for AKT activation in stromal fibroblasts remains under current investigation. Nevertheless, it has been demonstrated that TGF$\beta 1$ can activate AKT and focal adhesion kinase (FAK) to render myofibroblasts anoikis-resistant (Horowitz et al. 2007). Also, AKT phosphorylation can be affected by $\beta 1$ integrin in a PI3K-independent manner in fibroblasts (Pankov et al. 2003). The same fibroblast with a specific $\beta 1$-integrin tail mutation, which maintains low AKT levels, is more vulnerable to apoptosis than fibroblasts with wild-type $\beta 1$-integrin.

Using the organotypic 3D culturing system not only facilitates manipulation of the cancer epithelium, but also makes it possible to manipulate stromal components, such as directly comparing the various fibroblastic sources and their ability to induce tumor differentiation and/or invasion. We believe that the results in this study open several avenues to investigate stromagenic influences in tumor development, progression, and invasion.

\section{Materials and methods}

Cell culture

Primary human esophageal keratinocytes, designated as EPC2, were established as described previously (Andl et al. 2003). Cells were maintained at $37^{\circ} \mathrm{C}$ and $5 \% \mathrm{CO}_{2}$ using keratinocyte-SFM medium (KSFM; Invitrogen) supplemented with $40 \mu \mathrm{g} / \mathrm{mL}$ bovine pituitary extract (Invitrogen), $1.0 \mathrm{ng} / \mathrm{mL}$ EGF (Invitrogen), $100 \mathrm{U} / \mathrm{mL}$ penicillin, and $100 \mu \mathrm{g} / \mathrm{mL}$ streptomycin (Invitrogen).
TE12 cells, an established esophageal squamous cancer cell line, were cultured under standard conditions as described previously (Okano et al. 2000). For EGFR phosphorylation studies, cells were starved overnight in keratinocyte basal medium (KBM) that does not contain EGF (Cambrex Bio Science) followed by stimulation with EGF $(10 \mathrm{ng} / \mathrm{mL})$.

\section{Antibodies}

The antibody against EGFR (Ab-12) used for immunoblotting was obtained from NeoMarkers. The EGFR (SC-03) antibody used for immunohistochemistry was obtained from Santa Cruz Biotechnology, Inc. The antibodies against phospho-EGFR (Tyr 845, Tyr 1045, Tyr 1068, and Tyr 1173), phospho-AKT (Ser 473 and Thr 308), and total-AKT were purchased from Cell Signaling. The MMP-9 antibody was purchased from Chemicon International, Inc. The monoclonal antibody against p53 (Ab-6) was obtained from Oncogene Research Products, and for immunohistochemistry, a p53 (DO7) antibody was purchased from Vector Laboratories. The mouse monoclonal anti-E-cadherin was from Transduction Laboratories, and the chicken anti-vimentin was from Novus Biologicals. Control anti- $\beta$-actin antibody was purchased from Sigma. Anti-mouse and anti-rabbit horseradish peroxidase (HRP)-conjugated antibodies were purchased from Amersham Pharmacia Biotech. Biotinylated anti-chicken was detected with an $\mathrm{ABC}$ kit (Vector).

\section{Western blotting}

For Western blot analysis, cells were lysed in lysis buffer (10 $\mathrm{mM}$ Tris. $\mathrm{HCl}$ at $\mathrm{pH} 7.4,150 \mathrm{mM} \mathrm{NaCl}, 1 \%$ Nonidet P-40, $0.1 \%$ sodium deoxycholate, $0.1 \%$ SDS, $1 \mathrm{mM}$ EDTA, $2 \mathrm{mM}$ sodium orthovanadate, protease inhibitor tablet [Roche Molecular Biochemicals]). Protein concentration was determined by the BioRad protein assay (Bio-Rad). Fifteen micrograms of protein were run on a $4 \%-12 \%$ SDS-PAGE gel (Invitrogen) and transferred to a polyvinylidene difluoride membrane (Immobilon-P; Millipore). Membranes were blocked in 5\% nonfat milk (Bio-Rad) in TBS-T (10 mM Tris, $150 \mathrm{mM} \mathrm{NaCl}$ at $\mathrm{pH}$ 8.0, 0.1\% Tween 20) for $1 \mathrm{~h}$ at room temperature. Membranes were then probed with primary antibody diluted in $5 \%$ milk in TBS-T overnight at $4^{\circ} \mathrm{C}$, washed with TBS-T, incubated with anti-mouse or anti-rabbit horseradish peroxidase-conjugated secondary antibodies (GE Biotech; 1:3000 in TBS-T) for $1 \mathrm{~h}$ at room temperature, and washed in TBS-T. The signal was visualized using an enhanced chemiluminescence solution (ECL Plus; Amersham Pharmacia Biotech) and exposed to Blue Lite Autorad film (ISC-BioExpress).

\section{ShRNA and siRNA constructs}

Human retroviral shRNAmir against MMP-9, AKT1, and AKT2 and Expression Arrest eGFP control shRNA vector as a control were purchased from Open Biosystems. The control siRNAs and siRNAs specific for human AKT1 and AKT2 (validated siRNA) and MMP-9 were purchased from Ambion. Cells were transfected with a cationic lipid (LipofectAMINE 2000; Invitrogen) according to the manufacturer's protocols. The effectiveness of knockdown was confirmed by Western blotting with specific antibodies.

\section{Retroviral vectors and stable transduction}

Stable transduction of primary esophageal cells with retroviral vectors was described previously (Andl et al. 2003; Harada et al. 2003; Takaoka et al. 2004). Briefly, pFB-neo retroviral vectors (Stratagene) containing the entire coding sequence for the hu- 
man EGFR (pFB-neo-WT-hEGFR), pBabe-zeo-p53 ${ }^{\mathrm{R} 175 \mathrm{H}}$, or pBabe-puro-p53 $3^{\mathrm{R} 175 \mathrm{H}}$ were transfected into Phoenix-Ampho packaging cells (gift of Dr. Garry Nolan, Stanford University, Palo Alto, CA) using LipofectAMINE 2000 reagent (Invitrogen), according to the manufacturer's instructions. Culture supernatants from individual Phoenix-Ampho cells were used to infect EPC2-hTERT cells. Cells were passaged $48 \mathrm{~h}$ after infection and selected with G418 $(300 \mu \mathrm{g} / \mathrm{mL})$, puromycin $(0.5 \mu \mathrm{g} / \mathrm{mL})$, or zeo$\operatorname{cin}(10 \mu \mathrm{g} / \mathrm{mL})$ (Invitrogen) for a period of $7 \mathrm{~d}$, resulting in generation of control EPC2-hTERT-neo-zeo or EPC2-hTERTneo-puro, EPC2-hTERT-neo-p53 ${ }^{\text {175H }}$, EPC2-hTERT-EGFR-zeo, or EPC2-hTERT-EGFR-puro, and EPC2-hTERT-EGFR-p53 ${ }^{\text {R175H }}$ cells. Independent infections and selections were performed to generate two additional cell lines of each genotype.

The retroviral vector pWZLneo was used to express the conditionally active AKT construct myrAKT $\Delta 4$-129-ER (myrAKTER) (Kohn et al. 1998). This myristolated AKT, fused to the estrogen receptor, permits constitutive localization to the cell membrane with activation induced by tamoxifen addition to the culture medium, resulting in the activation of ectopically expressed AKT.

\section{Migration and invasion assays}

For migration assays, Boyden chambers $(8-\mu \mathrm{m}$ pore size, FluoroBlok-HTS inserts; BD Biosciences) were used. For invasion assays, insert plates $(8-\mu \mathrm{m}$ pore size; FluoroBlock; 24 -well insert) coated with $\mathrm{BD}$ Matrigel matrix were used. Inserts were placed in a 24-well plate containing Full KSFM medium with serum to stimulate cell migration and invasion. Cells $\left(5 \times 10^{4}\right)$ in serum-free medium were placed in each insert. Twenty-four hours later, migrating or invading cells were labeled with 4 $\mu \mathrm{g} / \mathrm{mL}$ Calcein AM dye (Invitrogen) in HANKS buffer for $1 \mathrm{~h}$. The labeled cells were then read on a Synergy HT multidetection microplate reader (BioTek) at 485-nm excitation and 528$\mathrm{nm}$ detection. All experiments were performed in triplicate in three independent cell lines for each genotype.

\section{Fibroblast isolation and characterization}

For fibroblast isolation, tissues were washed four times with sterile Dulbecco's modified Eagle's medium (DMEM) with antibiotics ( $20 \%$ FBS, $0.25 \%$ gentamycin, $0.1 \%$ Fungizone). Tissues were then cut lengthwise under sterile conditions, mixed with dispase, and incubated overnight in $50-\mathrm{mL}$ conical tubes with slow shaking at $4^{\circ} \mathrm{C}$. The dermis or esophageal submucosas were then carefully peeled away from the epidermis or mucosa, respectively. The dermis or esophageal submucosas were then placed in $0.5 \%$ trypsin for $10 \mathrm{~min}$ at $37^{\circ} \mathrm{C}$, followed by washing with a $5 \times$ volume of $250 \mathrm{mg} / \mathrm{L}$ soybean trypsin inhibitor. Individual cells were then collected and washed in medium containing antibiotics and placed in 10\% DMEM. To verify the purity of the fibroblasts, Western blotting was performed to confirm that cells were vitmentin positive and E-cadherin negative. Functionally, the fibroblasts were tested also for the ability to induce constriction of the ECM in organotypic culture.

\section{Organotypic culture}

To grow human esophageal epithelial cells (keratinocytes) in organotypic culture, 3D collagen/Matrigel matrices, containing $76.7 \%$ bovine tendon acid-extracted collagen (Organogenesis), Matrigel Matrix (BD Bioscience), $1 \times$ minimal essential medium with Earle's salts (BioWhittaker), 1.68 mM L-glutamine (Cellgro), $10 \%$ fetal bovine serum (Hyclone), $0.15 \%$ sodium bicarbonate (BioWhittaker), and $7.5 \times 10^{4}$ human fetal or adult esophageal fibroblasts or human fetal skin fibroblasts were generated. These matrices were allowed to contract for $7 \mathrm{~d}$, at which point $5 \times 10^{5}$ human esophageal epithelial cells were seeded on top of the matrices. Following addition of keratinocytes, cultures were fed with Epidermalization I medium for $2 \mathrm{~d}$, which is DMEM (JRH Biosciences)/Ham's F-12 (Invitrogen; 3:1) supplemented with $4 \mathrm{mM}$ L-glutamine, $0.5 \mu \mathrm{g} / \mathrm{mL}$ hydrocortisone, $0.1 \mathrm{mM}$ O-phosphorylethanolamine, $20 \mathrm{pM}$ triiodothyronine, $0.18 \mathrm{mM}$ adenine, $1.88 \mathrm{mM} \mathrm{CaCl}_{2}, 4 \mathrm{pM}$ progesterone (Sigma); $10 \mu \mathrm{g} / \mathrm{mL}$ insulin, $10 \mu \mathrm{g} / \mathrm{mL}$ transferrin, $5 \mathrm{mM}$ ethanolamine, $10 \mathrm{ng} / \mathrm{mL}$ selenium (ITES) (BioWhittaker), and $0.1 \%$ chelated newborn calf serum (Hyclone). For the following $2 \mathrm{~d}$, cultures were fed with Epidermalization II medium, which is identical to Epidermalization I medium except that it contains $0.1 \%$ unchelated newborn calf serum (instead of chelated). Then, cultures were raised to an air-liquid interface and cultured for $6 \mathrm{~d}$ in Epidermalization III medium, which contains the same growth supplements as Epidermalization I and II except that no progesterone is added and $2 \%$ newborn calf serum is used. Cultures were then harvested by fixing in $10 \%$ formaldehyde (Fisher), and later were paraffin-embedded. Conditioned medium was also collected at the time of harvesting.

\section{Pharmacological MMP-9 and AKT inhibition}

For MMP-9 inhibition studies, an MMP-9 inhibitor purchased from EMD Biosciences was used. The MMP-9 inhibitor is a potent and selective inhibitor of MMP-9 (IC50 = 5 nM). It inhibits MMP-1 at IC50 = $1.05 \mu \mathrm{M}$. This inhibitor complexes with the zinc cofactor that is required to keep MMP-9 in an active state (Levin et al. 2001). The MMP-9 inhibitor was added to the Epidermalization III medium (beginning at day 11) in increasing doses from $0.5 \mathrm{nM}$ to $500 \mathrm{nM}$. AKT inhibition in organotypic cultures was performed using the AKTi $1 / 2$ inhibitor purchased from Calbiochem. AKTi $1 / 2$ is a cell-permeable, potent, and selective inhibitor of Akt1/Akt2 activity (IC50 =58 nM, 210 $\mathrm{nM}$, and $2.12 \mu \mathrm{M}$ for AKT1, AKT2, and AKT3, respectively, in in vitro kinase assays). The inhibition is reported to be pleckstrin homology $(\mathrm{PH})$ domain-dependent. To specifically target the fibroblasts, the AKTi $1 / 2$ inhibitor ( $50 \mathrm{nM}$ ) was added to the media during the period of matrix contraction and prior to the addition of epithelial cells (days 1-7).

\section{Real-time PCR}

RNA was isolated from cells using Trizol reagent (Invitrogen), and cDNA was synthesized using the SuperScript first-strand synthesis system for RT-PCR (Invitrogen) according to the manufacturer's instructions. Primers for SYBR green real-time PCR were designed using the TaqMan probe software and were synthesized by Invitrogen. The following oligonucleotides were used as primers: (1) human MMP-9, 5'-GGACGATGCCTG CAACGT-3' (forward primer); 5'-ACAAATACAGCTGGTTC CCAATC-3' (reverse primer); (2) human glyceraldehydes-3phosphade dehydrogenase (GAPDH), 5'-CACCCACTCCTC CACCTTT-3' (forward primer); 5'-TCCACCACCCTGTTGC TGTAG-3' (reverse primer). GAPDH was used as the internal control. SYBR green real-time PCR was performed and analyzed using ABI PRISM 7000 sequence detection system software (PE Applied Biosystems) with reagents from the SYBR green PCR kit (PE Applied Biosystems) according to the manufacturer's instructions.

\section{Immunohistochemistry}

Immunohistochemistry was performed with the Vecta Elite kit (Vector Laboratories) following the manufacturer's protocol. 
Briefly, paraffin sections were pretreated with xylene and then microwaved for $10 \mathrm{~min}$ in the presence of $10 \mathrm{mM}$ citric acid buffer. Endogenous peroxidases were quenched using hydrogen peroxide before sections were blocked in avidin D-blocking reagent and biotin-blocking reagent. Sections were incubated with primary antibody overnight at $4^{\circ} \mathrm{C}$ and secondary antibody for $30 \mathrm{~min}$ at $37^{\circ} \mathrm{C}$, and then signal was developed using the $\mathrm{DAB}$ substrate kit for peroxidase (Vector Laboratories).

\section{Zymography}

Gelatin zymography was performed on $10 \%$ Novex precast polyacrylamide gel (Invitrogen) in the presence of $0.1 \%$ gelatin. Conditioned media $(20 \mu \mathrm{L})$ were loaded, and SDS-PAGE was performed using tris-glycine SDS buffer. Protein standards were run concurrently, and approximate molecular weights were determined. Protein content was assayed by the method of Bradford, and samples were mixed with equal volume of $2 \times$ SDS sample buffer (Invitrogen). Samples were incubated for $15 \mathrm{~min}$ at room temperature and were applied to gelatin or casein zymography gels. After electrophoresis (125 V, $90 \mathrm{~min})$, proteins were renatured within zymography renaturing buffer (Invitrogen) for $30 \mathrm{~min}$ at room temperature under continuous shaking conditions and were then placed overnight at $37^{\circ} \mathrm{C}$ in developing buffer (Invitrogen). Substrate was visualized by Coomassie brilliant blue staining $10.1 \%$ Coomassie brilliant blue, $45.5 \%$ methanol, $9 \%$ acetic acid).

\section{MMP-9 activity assay}

Conditioned media of organotypic cultures were collected on day 15 and centrifuged at $10,000 \mathrm{~g}$ at $4^{\circ} \mathrm{C}$, and $100 \mu \mathrm{L}$ were used to detect MMP-9 enzymatic activity in duplicate using the SenzoLyte Plus MMP-9 assay kit from Anaspec according to the manufacturer's instructions. In brief, a specific MMP-9 antibody was used in combination with an MMP-9 fluorogenic substrate 5-FAM/QXL 520. In addition, $1 \mathrm{mM}$ p-Aminophenylmercuric Acetate (AMPA) was used to activate a pro-MMP-9 standard and pro-MMP-9 in samples. Fluorescent signal was monitored at Excitation/Emmition $=490-520 \mathrm{~nm}$ upon MMP9-induced cleavage of the QXL FRET substrate using a fluorescence microplate reader (Bio-Tek FLx800).

\section{ECM stiffness measurements}

The stiffness of 3D organotypic culture ECMs was assessed by measuring the dynamic shear modulus $\left(\mathrm{G}^{\prime}\right)$ with a Rheometrics RFS-II instrument using cone-and-plate geometry with titanium surfaces. The cone had a diameter of $8 \mathrm{~mm}$. Cutouts of ECM of $8 \mathrm{~mm}$ in diameter and $1.7-4.0 \mathrm{~mm}$ in thickness were measured by a strain-controlled dynamic sweep test. Time-dependent measurements were done for $150 \mathrm{sec}$ with one time point every $15 \mathrm{sec}$ at $5 \mathrm{rad} / \mathrm{sec}$ and $2.0 \%$ strain. An average of all measurements was then calculated. All samples were tested in triplicate.

\section{Soft agar colony formation assays}

To assess anchorage-independent growth in soft agar, cells were suspended in $0.67 \%$ agarose containing DMEM-KBM (1:1) medium supplemented with $5 \%$ FCS, $30 \mu \mathrm{g} / \mathrm{mL} \mathrm{BPE}$, and $0.5 \mathrm{ng} /$ $\mathrm{mL}$ EGF, overlaid on top of a $1 \%$ agarose containing the medium $\left(2.5 \times 10^{4}\right.$ cells per well), and allowed to form colonies for 2 wk at $37^{\circ} \mathrm{C}$ under $5 \% \mathrm{CO}_{2}$. Colonies were counted under an Eclipse TS100 inverted microscope (Nikon).

\section{Subcutaneous implantations in nude mice}

Studies were carried out in accordance with protocols approved by the Institutional Animal Care and Use Committee. Luciferase-positive EPC-hTERT-EGFR-puro and EPC-hTERT-EGFR$\mathrm{p} 53^{\mathrm{R} 175 \mathrm{H}}$ cells (two independent cell lines) were obtained by stably transducing the cell lines with the retroviral vector pFBneo/luc. For subcutaneous injections, 5- to 8-wk-old female athymic mice (NCRNU-M; Taconic), divided into three groups of four mice, were subcutaneously injected in the dorsal flanks (two or four injection sites per mouse) with a 1:1 mix of Matrigel:DMEM/KBM containing $3.0 \times 10^{6}$ luciferase-expressing esophageal epithelial cells in suspension. Bioluminescence measurements were performed on day 9 and day 16 after injection. On day 16, the mice were sacrificed, and tumors were assessed by histology and immunohistochemistry.

\section{Acknowledgments}

We thank members of the Rustgi laboratory for discussions. Imaging was performed at the Bioluminescence Molecular Imaging Core facility at the University of Pennsylvania (supported in part by NIH grant CA105008). We are grateful to Dr. Paul Janmey, Jessamine Winer, and Charles G. Miller for assistance with the ECM stiffness measurements. We acknowledge the Morphology Core (S. Mitchell, G. Swain), Molecular Biology/ Gene Expression Core (G. Wu, S. Keilbaugh), and Cell Culture Core (R. Carroll). This work was supported by NIH/NCI PO1CA098101 grant (to A.K.R., T.O., C.Z.M., H.N., C.D.A., D.B.S., W.S.E.-D., M.H., and A.J.K.-S.), NIH/NRSA F32-DK075230 (to C.Z.M.), NIH/NRSA F32-CA103085 (to D.B.S.), NIH/NIDDK K01-DK066205 and NIH/NIDDK R01-DK077005 (to H.N.), an AGA/FDHN Research Scholar Award (to C.D.A.), and NIH/ NIDDK Center for Molecular Studies in Digestive and Liver Diseases (P30-DK050306).

\section{References}

Amatangelo, M.D., Bassi, D.E., Klein-Szanto, A.J., and Cukierman, E. 2005. Stroma-derived three-dimensional matrices are necessary and sufficient to promote desmoplastic differentiation of normal fibroblasts. Am. J. Pathol. 167: 475-488.

Andl, C.D., Mizushima, T., Nakagawa, H., Oyama, K., Harada, H., Chruma, K., Herlyn, M., and Rustgi, A.K. 2003. Epidermal growth factor receptor mediates increased cell proliferation, migration, and aggregation in esophageal keratinocytes in vitro and in vivo. J. Biol. Chem. 278: 1824-1830.

Beacham, D.A. and Cukierman, E. 2005. Stromagenesis: The changing face of fibroblastic microenvironments during tumor progression. Semin. Cancer Biol. 15: 329-341.

Boyd, D. 1996. Invasion and metastasis. Cancer Metastasis Rev. 15: 77-89.

Cox, G., Jones, J.L., and O'Byrne, K.J. 2000. Matrix metalloproteinase 9 and the epidermal growth factor signal pathway in operable non-small cell lung cancer. Clin. Cancer Res. 6: 2349-2355.

Ellerbroek, S.M., Halbleib, J.M., Benavidez, M., Warmka, J.K., Wattenberg, E.V., Stack, M.S., and Hudson, L.G. 2001. Phosphatidylinositol 3-kinase activity in epidermal growth factor-stimulated matrix metalloproteinase-9 production and cell surface association. Cancer Res. 61: 1855-1861.

Engelhardt, M., Drullinsky, P., Guillem, J., and Moore, M.A. 1997. Telomerase and telomere length in the development and progression of premalignant lesions to colorectal cancer. Clin. Cancer Res. 3: 1931-1941. 
Enzinger, P.C. and Mayer, R.J. 2003. Esophageal cancer. N. Engl. J. Med. 349: 2241-2252.

Gu, Z.D., Li, J.Y., Li, M., Gu, J., Shi, X.T., Ke, Y., and Chen, K.N. 2005. Matrix metalloproteinases expression correlates with survival in patients with esophageal squamous cell carcinoma. Am. J. Gastroenterol. 100: 1835-1843.

Gupta, G.P. and Massague, J. 2006. Cancer metastasis: Building a framework. Cell 127: 679-695.

Harada, H., Nakagawa, H., Oyama, K., Takaoka, M., Andl, C.D., Jacobmeier, B., von Werder, A., Enders, G.H., Opitz, O.G., and Rustgi, A.K. 2003. Telomerase induces immortalization of human esophageal keratinocytes without p16INK4a inactivation. Mol. Cancer Res. 1: 729-738.

Horowitz, J.C., Rogers, D.S., Sharma, V., Vittal, R., White, E.S., Cui, Z., and Thannickal, V.J. 2007. Combinatorial activation of FAK and AKT by transforming growth factor- $\beta 1$ confers an anoikis-resistant phenotype to myofibroblasts. Cell. Signal. 19: 761-771.

Joerger, A.C., Ang, H.C., Veprintsev, D.B., Blair, C.M., and Fersht, A.R. 2005. Structures of p53 cancer mutants and mechanism of rescue by second-site suppressor mutations. J. Biol. Chem. 280: 16030-16037.

Kim, J., Yu, W., Kovalski, K., and Ossowski, L. 1998. Requirement for specific proteases in cancer cell intravasation as revealed by a novel semiquantitative PCR-based assay. Cell 94: 353-362.

Kohn, A.D., Barthel, A., Kovacina, K.S., Boge, A., Wallach, B., Summers, S.A., Birnbaum, M.J., Scott, P.H., Lawrence Jr., J.C., and Roth, R.A. 1998. Construction and characterization of a conditionally active version of the serine/threonine kinase Akt. J. Biol. Chem. 273: 11937-11943.

Koyama, H., Iwata, H., Kuwabara, Y., Iwase, H., Kobayashi, S. and Fujii, Y. 2000. Gelatinolytic activity of matrix metalloproteinase-2 and -9 in oesophageal carcinoma; a study using in situ zymography. Eur. J. Cancer 36: 2164-2170.

Kupferman, M.E., Fini, M.E., Muller, W.J., Weber, R., Cheng, Y., and Muschel, R.J. 2000. Matrix metalloproteinase 9 promoter activity is induced coincident with invasion during tumor progression. Am. J. Pathol. 157: 1777-1783.

Lehrbach, D.M., Nita, M.E., and Cecconello, I. 2003. Molecular aspects of esophageal squamous cell carcinoma carcinogenesis. Arq. Gastroenterol. 40: 256-261.

Levin, J.I., Chen, J., Du, M., Hogan, M., Kincaid, S., Nelson, F.C., Venkatesan, A.M., Wehr, T., Zask, A., DiJoseph, J., et al. 2001. The discovery of anthranilic acid-based MMP inhibitors. Part 2: SAR of the 5-position and P1(1) groups Bioorg. Med. Chem. Lett. 11: 2189-2192.

Lin, Y., Miyamoto, H., Fujinami, K., Uemura, H., Hosaka, M., Iwasaki, Y., and Kubota, Y. 1996. Telomerase activity in human bladder cancer. Clin. Cancer Res. 2: 929-932.

Liotta, L.A., Tryggvason, K., Garbisa, S., Hart, I., Foltz, C.M., and Shafie, S. 1980. Metastatic potential correlates with enzymatic degradation of basement membrane collagen. $\mathrm{Na}$ ture 284: 67-68.

Liotta, L.A., Steeg, P.S., and Stetler-Stevenson, W.G. 1991. Cancer metastasis and angiogenesis: An imbalance of positive and negative regulation. Cell 64: 327-336.

Maffini, M.V., Soto, A.M., Calabro, J.M., Ucci, A.A., and Sonnenschein, C. 2004. The stroma as a crucial target in rat mammary gland carcinogenesis. J. Cell Sci. 117: 1495-1502.

Mandard, A.M., Hainaut, P., and Hollstein, M. 2000. Genetic steps in the development of squamous cell carcinoma of the esophagus. Mutat. Res. 462: 335-342.

Mannello, F., Tonti, G., and Papa, S. 2005. Matrix metalloproteinase inhibitors as anticancer therapeutics. Curr. Cancer Drug Targets 5: 285-298.
McCabe, M.L. and Dlamini, Z. 2005. The molecular mechanisms of oesophageal cancer. Int. Immunopharmacol. 5: $1113-1130$.

McCawley, L.J., Li, S., Wattenberg, E.V., and Hudson, L.G. 1999. Sustained activation of the mitogen-activated protein kinase pathway. A mechanism underlying receptor tyrosine kinase specificity for matrix metalloproteinase-9 induction and cell migration. J. Biol. Chem. 274: 4347-4353.

Metzger, R., Schneider, P.M., Warnecke-Eberz, U., Brabender, J., and Holscher, A.H. 2004. Molecular biology of esophageal cancer. Onkologie 27: 200-206.

Mitsui, A., Kuwabara, Y., Iwase, H., Mitani, M., Shinoda, N., Sato, A., Toyama, T., Sugiura, M., Suzuki, T., Kato, J., et al. 2002. Telomerase activity in esophageal squamous cell carcinoma: Down-regulation by chemotherapeutic agent. $J$. Surg. Oncol. 79: 37-45.

Nair, K.S., Naidoo, R., and Chetty, R. 2005. Expression of cell adhesion molecules in oesophageal carcinoma and its prognostic value. J. Clin. Pathol. 58: 343-351.

Okano, J., Gaslightwala, I., Birnbaum, M.J., Rustgi, A.K., and Nakagawa, H. 2000. Akt/protein kinase B isoforms are differentially regulated by epidermal growth factor stimulation. J. Biol. Chem. 275: 30934-30942.

Okano, J., Snyder, L., and Rustgi, A.K. 2003. Genetic alterations in esophageal cancer. Methods Mol. Biol. 222: 131-145.

Oyama, K., Okawa, T., Nakagawa, H., Takaoka, M., Andl, C.D., Kim, S.H., Klein-Szanto, A., Diehl, J.A., Herlyn, M., ElDeiry, W., et al. 2007. AKT induces senescence in primary esophageal epithelial cells but is permissive for differentiation as revealed in organotypic culture. Oncogene 26: 23532364.

Ozawa, S., Ueda, M., Ando, N., Shimizu, N., and Abe, O. 1989. Prognostic significance of epidermal growth factor receptor in esophageal squamous cell carcinomas. Cancer 63: 21692173.

Pankov, R., Cukierman, E., Clark, K., Matsumoto, K., Hahn, C., Poulin, B., and Yamada, K.M. 2003. Specific $\beta 1$ integrin site selectively regulates Akt/protein kinase B signaling via local activation of protein phosphatase 2A. J. Biol. Chem. 278: 18671-18681.

Paszek, M.J. and Weaver, V.M. 2004. The tension mounts: Mechanics meets morphogenesis and malignancy. J. Mammary Gland Biol. Neoplasia 9: 325-342.

Paszek, M.J., Zahir, N., Johnson, K.R., Lakins, J.N., Rozenberg, G.I., Gefen, A., Reinhart-King, C.A., Margulies, S.S., Dembo, M., Boettiger, D., et al. 2005. Tensional homeostasis and the malignant phenotype. Cancer Cell 8: 241-254.

Polette, M., Nawrocki-Raby, B., Gilles, C., Clavel, C., and Birembaut, P. 2004. Tumour invasion and matrix metalloproteinases. Crit. Rev. Oncol. Hematol. 49: 179-186.

Radisky, D., Hagios, C., and Bissell, M.J. 2001. Tumors are unique organs defined by abnormal signaling and context. Semin. Cancer Biol. 11: 87-95.

Reddy, K.B., Krueger, J.S., Kondapaka, S.B., and Diglio, C.A. 1999. Mitogen-activated protein kinase (MAPK) regulates the expression of progelatinase B (MMP-9) in breast epithelial cells. Int. J. Cancer 82: 268-273.

Samantaray, S., Sharma, R., Chattopadhyaya, T.K., Gupta, S.D., and Ralhan, R. 2004. Increased expression of MMP-2 and MMP-9 in esophageal squamous cell carcinoma. J. Cancer Res. Clin. Oncol. 130: 37-44.

Sato, N., Maehara, N., Mizumoto, K., Nagai, E., Yasoshima, T., Hirata, K., and Tanaka, M. 2001. Telomerase activity of cultured human pancreatic carcinoma cell lines correlates with their potential for migration and invasion. Cancer 91: 496504 
Sengupta, S. and Harris, C.C. 2005. p53: Traffic cop at the crossroads of DNA repair and recombination. Nat. Rev. Mol. Cell Biol. 6: 44-55.

Simon, C., Goepfert, H., and Boyd, D. 1998. Inhibition of the p38 mitogen-activated protein kinase by SB 203580 blocks PMA-induced Mr 92,000 type IV collagenase secretion and in vitro invasion. Cancer Res. 58: 1135-1139.

Simon, M., Park, T.W., Leuenroth, S., Hans, V.H., Loning, T., and Schramm, J. 2000. Telomerase activity and expression of the telomerase catalytic subunit, hTERT, in meningioma progression. J. Neurosurg. 92: 832-840.

Sunpaweravong, P., Sunpaweravong, S., Puttawibul, P., Mitarnun, W., Zeng, C., Baron, A.E., Franklin, W., Said, S., and Varella-Garcia, M. 2005. Epidermal growth factor receptor and cyclin D1 are independently amplified and overexpressed in esophageal squamous cell carcinoma. J. Cancer Res. Clin. Oncol. 131: 111-119.

Takaoka, M., Harada, H., Deramaudt, T.B., Oyama, K., Andl, C.D., Johnstone, C.N., Rhoades, B., Enders, G.H., Opitz, O.G., and Nakagawa, H. 2004. Ha-Ras(G12V) induces senescence in primary and immortalized human esophageal keratinocytes with p53 dysfunction. Oncogene 23: 6760-6768.

Unger, M. and Weaver, V.M. 2003. The tissue microenvironment as an epigenetic tumor modifier. Methods Mol. Biol. 223: 315-347.

Vihinen, P., Ala-aho, R., and Kahari, V.M. 2005. Matrix metalloproteinases as therapeutic targets in cancer. Curr. Cancer Drug Targets 5: 203-220.

Vogelstein, B. and Kinzler, K.W. 2004. Cancer genes and the pathways they control. Nat. Med. 10: 789-799.

Wittekind, C. and Neid, M. 2005. Cancer invasion and metastasis. Oncology 69 (Suppl. 1): 14-16.

Zeigler, M.E., Chi, Y., Schmidt, T., and Varani, J. 1999. Role of ERK and JNK pathways in regulating cell motility and matrix metalloproteinase 9 production in growth factor-stimulated human epidermal keratinocytes. J. Cell. Physiol. 180: 271-284.

Zhang, D.K., Ngan, H.Y., Cheng, R.Y., Cheung, A.N., Liu, S.S., and Tsao, S.W. 1999. Clinical significance of telomerase activation and telomeric restriction fragment (TRF) in cervical cancer. Eur. J. Cancer 35: 154-160. 


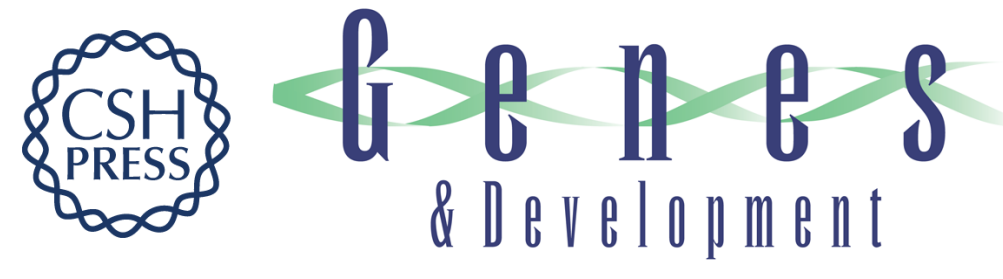

\section{The functional interplay between EGFR overexpression, hTERT activation, and p53 mutation in esophageal epithelial cells with activation of stromal fibroblasts induces tumor development, invasion, and differentiation}

Takaomi Okawa, Carmen Z. Michaylira, Jiri Kalabis, et al.

Genes Dev. 2007, 21:

Access the most recent version at doi:10.1101/gad.1544507
Supplemental
Material
http://genesdev.cshlp.org/content/suppl/2007/10/18/21.21.2788.DC1
References
This article cites 53 articles, 14 of which can be accessed free at:
http://genesdev.cshlp.org/content/21/21/2788.full.html\#ref-list-1
License
Email Alerting
Receive free email alerts when new articles cite this article - sign up in the box at the top
Service
right corner of the article or click here.

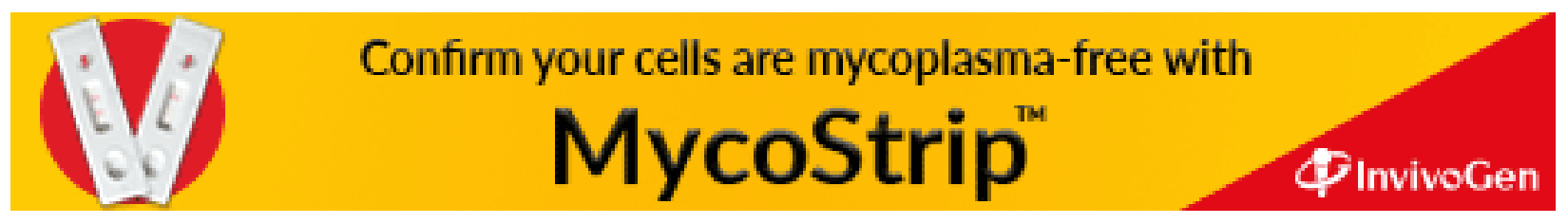

